Supporting Information

\title{
Surpassing the Organic Cathode Performance for Lithium-Ion Batteries with Robust Fluorinated Covalent Quinazoline Networks
}

Zhenzhen Yang, ${ }^{\dagger}$ Tao Wang, † Hao Chen, Xian Suo, Phillip Halstenberg, Hailong Lyu, Wei Jiang, Shannon M. Mahurin, Ilja Popovs, ${ }^{*}$ Sheng Dai*

Dr. Z. Yang, Dr. T. Wang, Dr. P. William, Dr. S.M. Mahurin, Dr. I. Popovs, and Dr. S.

Dai

Chemical Sciences Division, Oak Ridge National Laboratory, Oak Ridge, TN 37831 , USA.

Dr. H. Chen, Dr. X. Suo, Dr. P. Halstenberg, Dr. H. Lyu, Dr. W. Jiang, and Dr. S. Dai

Department of Chemistry, The University of Tennessee, Knoxville, TN, 37996, USA.

\section{Corresponding Author}

*E-mail: popovsi@ornl.gov; dais@ornl.gov

these authors contributed equally to this study. 


\section{Table of contents}

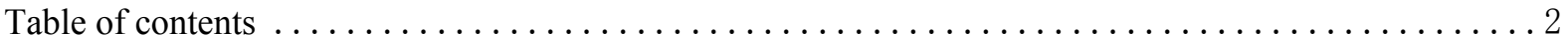

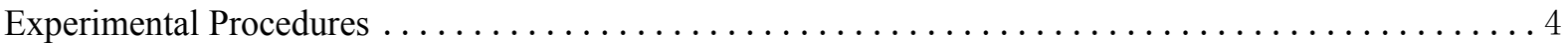

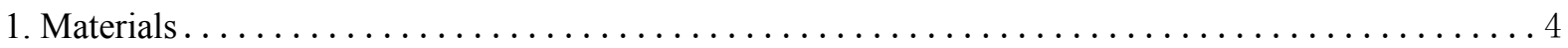

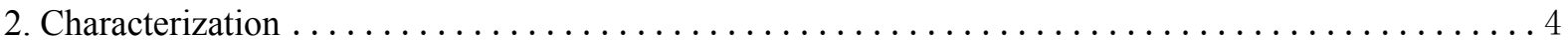

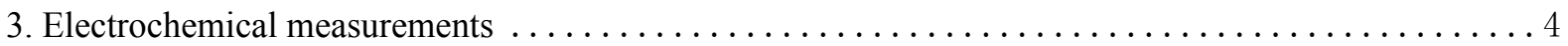

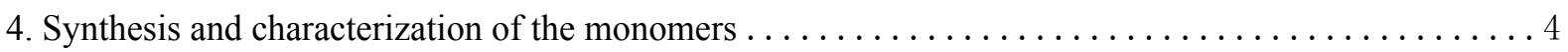

5. Synthesis of the model compound fluorinated tricycloquinazoline (m-F-TCQ) $\ldots \ldots \ldots \ldots \ldots \ldots 7$

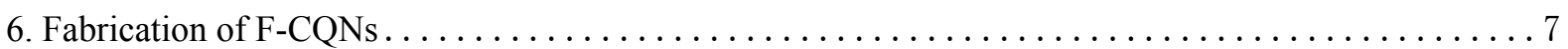

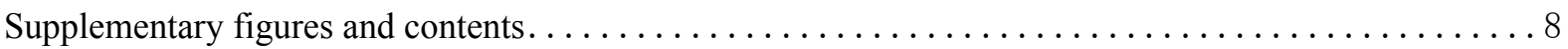

Figure S1 ESI-MS spectrum and ${ }^{1} \mathrm{H},{ }^{19} \mathrm{~F},{ }^{13} \mathrm{C}$ NMR spectra of m-F-TCQ $\ldots \ldots \ldots \ldots \ldots \ldots \ldots$

Figure S2 (A) TGA result of the mixture composed of 2,5-diamino-3,6-difluoroterephthalonitrile and $\mathrm{ZnCl}_{2}$ (molar ratio 1: 10, same as that used for F-CQNs synthesis) under $\mathrm{N}_{2}$ atmosphere in the range of $25 \sim 800{ }^{\circ} \mathrm{C}$ with a ramping rate of $5{ }^{\circ} \mathrm{C} \mathrm{min}^{-1}$. (B O) Molecular weight, structure, and curves of different gaseous products formed along with the time and heating temperature. . . . . . . . . . . . . . . . 13 Figure S3 TGA results of F-CQN-1-200 and F-CQN-1-600 under nitrogen and air atomosphere from 25 to

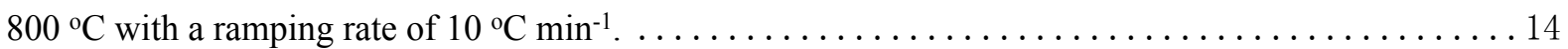

Figure S4 XPS survey spectra of F-CQN-1-400 F-CQN-1-700 $\ldots \ldots \ldots \ldots \ldots \ldots \ldots \ldots \ldots \ldots \ldots \ldots \ldots$

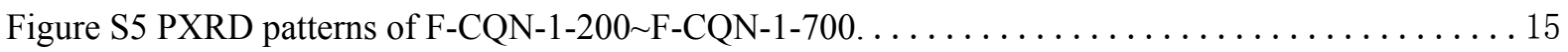

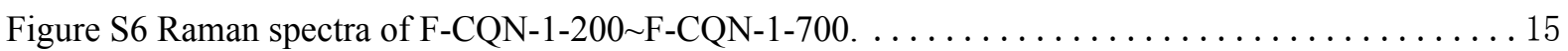

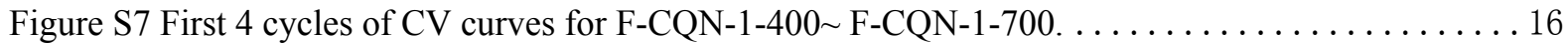

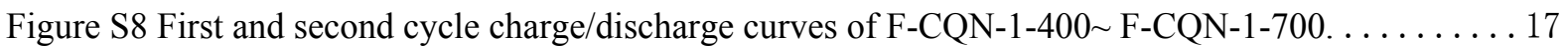

Figure S9 a) GITT curve of F-CQN-1-600 which were acquired with a current flux of $5 \mathrm{~mA} \mathrm{~g}^{-1}$ for $30 \mathrm{~min}$ in the potential range of $1.8-4.2 \mathrm{~V}$, followed by resting for $2 \mathrm{~h}$ to reach the steady state; $\mathrm{b}$ ) The

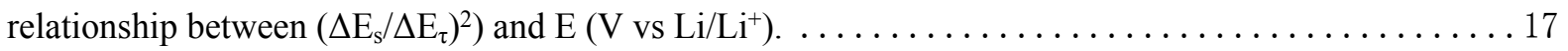

Figure S10 (a) and (b) SEM image of F-CQN-1-600 after cycling; (c) and (d) SEM image of F-CQN-1-700

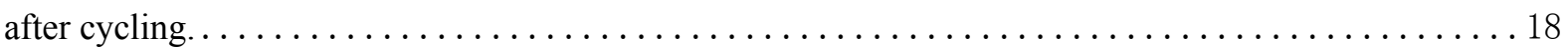

Figure S11 SEM element mapping of F-CQN-1-600 after charging process. $\ldots \ldots \ldots \ldots \ldots \ldots \ldots$

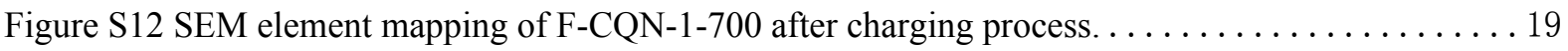

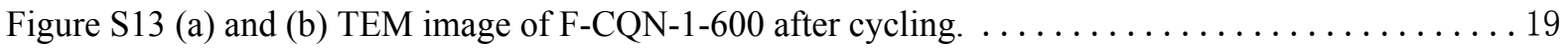

Figure S14. XPS spectra for charged and discharged F-CQN-1-600. a) Li 1s; b) P 2p; c) survey spectra.. 20

Table S1. Surface composition of the charged and discharged F-CQN-1-600 calculated from XPS results.

Figure S15 Electrochemical impedance spectra (EIS) of the half-cells at OCV using different active

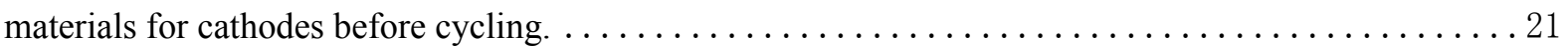

Table S2 Summary of the representative organic cathode materials for lithium ion batteries. . . . . . 22

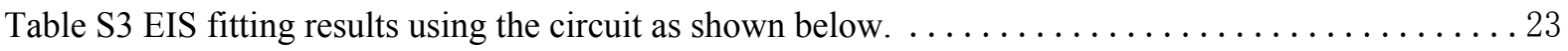

Figure S16 Room temperature electron paramagnetic resonance (EPR) spectra of (A) F-CQN-1-400, (B)

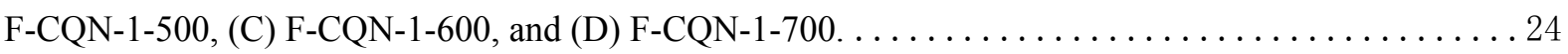

Figure S17 (A, B) $\mathrm{N}_{2}$ adsorption and desorption isotherm curves at $77 \mathrm{~K}$ and Pore-size-distribution curves 


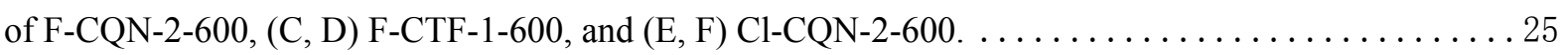

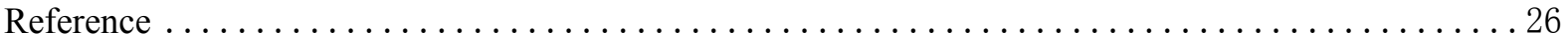




\section{Experimental Procedures}

\section{Materials}

Zinc chloride $\left(\mathrm{ZnCl}_{2}\right)$, 1,4-dicyanotetrafluorobenzene, 2-amino-3-fluorobenzonitrile, and battery grade ethylene carbonate (EC), dimethyl carbonate (DMC), lithium hexafluorophosphate $\left(\mathrm{LiPF}_{6}\right)$ were purchased from commercial sources (Fisher scientific and Sigma-Aldrich, and BASF) and used without further purification, unless indicated otherwise.

\section{Characterization}

FTIR spectra of the samples were collected on a TENSOR 27 FTIR at a resolution of $2 \mathrm{~cm}^{-1}$ in the spectral range from 4000 to 500 $\mathrm{cm}^{-1}$. Solid-state ${ }^{13} \mathrm{C}$ NMR was performed using a Solid-State Varian INOVA $400 \mathrm{MHz}$. The powder X-ray diffraction (PXRD) data were recorded with a PANalytical Empyrean diffractometer, operated at $45 \mathrm{kV}$ and $40 \mathrm{~mA}$ (scanning step: $0.02{ }^{\circ}$ per step). The diffraction patterns were recorded in the range of $10-50^{\circ} . \lambda=0.1540598 \mathrm{~nm}$. X-ray photoelectron spectroscopy (XPS) measurements: XPS experiments were performed with a PHI 3056 spectrometer equipped with an Al anode source operated at 15 $\mathrm{KV}$ and an applied power of $350 \mathrm{~W}$ and a pass energy of $93.5 \mathrm{eV}$. Samples were mounted on foil since the C1s binding energy was used to calibrate the binding energy shifts of the sample $(\mathrm{C} 1 \mathrm{~s}=284.8 \mathrm{eV})$. The nitrogen adsorption and desorption isotherms were measured at $77 \mathrm{~K}$ under a Gemini 2360 surface area analyzer. The samples were outgassed at $150{ }^{\circ} \mathrm{C}$ for $16 \mathrm{~h}$ before the measurements. Surface areas were calculated from the adsorption data using Brunauer-Emmett-Teller (BET) methods. The pore-size-distribution curves were obtained from the adsorption branches using non-local density functional theory (NLDFT) method. SEM imaging was performed by using a Zeiss Auriga microscope with an electron beam operation of $5 \mathrm{keV}$, which is a dual beam FIB (Focused Ion Beam) with a field-emission electron column for high-resolution electron imaging and a Canion Ga+ column for precision ion beam milling. Transmission electron microscopy (TEM) were conducted on an aberration-corrected FEI Titan S 80-300. The elemental compositions of the products were analyzed by energy dispersive X-ray spectroscopy (EDS) on a SEM instrument with an EDAX accessory. TGA-MS was conducted on Discovery TGA under $\mathrm{N}_{2}$ atmosphere with a ramping rate of $5^{\circ} \mathrm{C} \mathrm{min}^{-1}$.

\section{Electrochemical measurements}

The electrodes based on F-CQNs were obtained by casting well homogenized slurries of active material, acetylene black and polyvinylidene fluoride (PVDF) binder with a weight ratio of 7:2:1 in N-methylpyrrolidone (NMP) on aluminum foils. After solvent evaporation, the electrodes were dried thoroughly in a vacuum oven at $100^{\circ} \mathrm{C}$ for $12 \mathrm{~h}$ and cut into discs with a diameter of $10 \mathrm{~mm}$. The as-prepared electrodes have similar active material loading of $1 \mathrm{mg} \mathrm{cm}^{-2}$. All the coin cells for electrochemical measurement were assembled in an argon filled glovebox with the oxygen and moisture levels below $0.5 \mathrm{ppm}$. LIB half-cells were assembled with the F-CQN electrodes as the cathode, lithium metal foils as both counter and reference electrodes, Celgard 2320 as separator and 1.2 $\mathrm{M} \mathrm{LiPF}_{6}$ dissolved in EC and EMC (3: 7, vol.) as the electrolyte. To aid electrolyte wetting, coin cells were allowed to rest for $4 \mathrm{~h}$ before cycling. The coin cells were galvanostatically cycled on a LAND CT2001A battery test system between 1.5 and $4.5 \mathrm{~V}$ at various current densities. Cyclic voltammogram (CV) data of the coin cells were recorded on a CHI 760E instrument at a scan rate of $1 \mathrm{mV} \mathrm{s}^{-1}$ in the voltage range of 1.5-4.5 V. Electrochemical impedance spectra (EIS) were measured on the same instrument with a amplitude of $5 \mathrm{mV}$ in the frequency range from $1 \mathrm{~Hz}$ to $100 \mathrm{kHz}$. Galvanostatic Intermittent Titration Technique (GITT) studies were performed on a BioLogic MPG2 system 5 by employing a constant $5 \mathrm{~mA} / \mathrm{g}$ current pulse for $1800 \mathrm{~s}$ followed by a $2 \mathrm{~h}$ rest within potential range of $1.8-4.2 \mathrm{~V}$.

\section{Synthesis and characterization of the monomers}

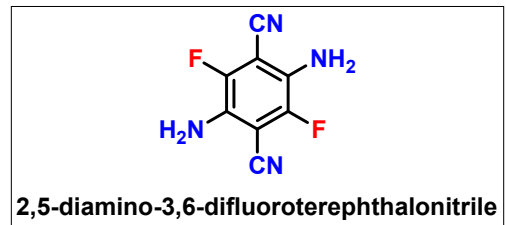


The title compound was prepared in a simple 2-step procedure: 2,3,5,6-tetrafluoro1,4-dicyanobenzene (4.0 g, $20 \mathrm{mmol})$ was dissolved in DMSO $(35 \mathrm{ml})$ and an excess of tert-butylamine $(7.3 \mathrm{~g}, 100 \mathrm{mmol})$ was added to the solution in one portion. The reaction mixture was allowed to stir at room temperature for $6 \mathrm{~h}$ until the starting material has disappeared as judged by TLC and ${ }^{19} \mathrm{~F}$ NMR analysis of the reaction aliquot. Reaction mixture was poured into water under vigorous stirring and the precipitated product was filtered, washed with water and air dried. The obtained intermediate was dissolved in dichloromethane (250 ml) and excess of TfOH (15 g, $100 \mathrm{mmol})$ was carefully added causing the precipitation of the salt. This salt was filtered and washed with additional amount of fresh DCM $(2 \times 60 \mathrm{ml})$ and vacuum dried. The resulting salt was transferred into $500 \mathrm{ml}$ flask, water $(250 \mathrm{ml})$ was added followed by excess amount of $\mathrm{Et}_{3} \mathrm{~N}(20 \mathrm{~g}, 200 \mathrm{mmol})$. The precipitated yellow solid was filtered off, washed with water and vacuum dried, affording the title product $(4.9 \mathrm{~g})$ in $90 \%$ overall yield. ${ }^{1} \mathrm{H}$ NMR (400 MHz, DMSO- $\left.d_{6}\right) 5.80(\mathrm{~s}, 4 \mathrm{H}) .{ }^{19} \mathrm{~F} \mathrm{NMR}$ (376 MHz, DMSO- $\left.d_{6}\right)-130.40(\mathrm{~s}, 2 \mathrm{~F}) .{ }^{13} \mathrm{C}$ NMR (100 MHz, DMSO- $\left.d_{6}\right) 146.84(\mathrm{dd}, J=241,4.6 \mathrm{~Hz}), 128.82(\mathrm{dd}, J=5.1,7.1 \mathrm{~Hz})$, $111.69,92.54(\mathrm{t}, J=12.3 \mathrm{~Hz})$.
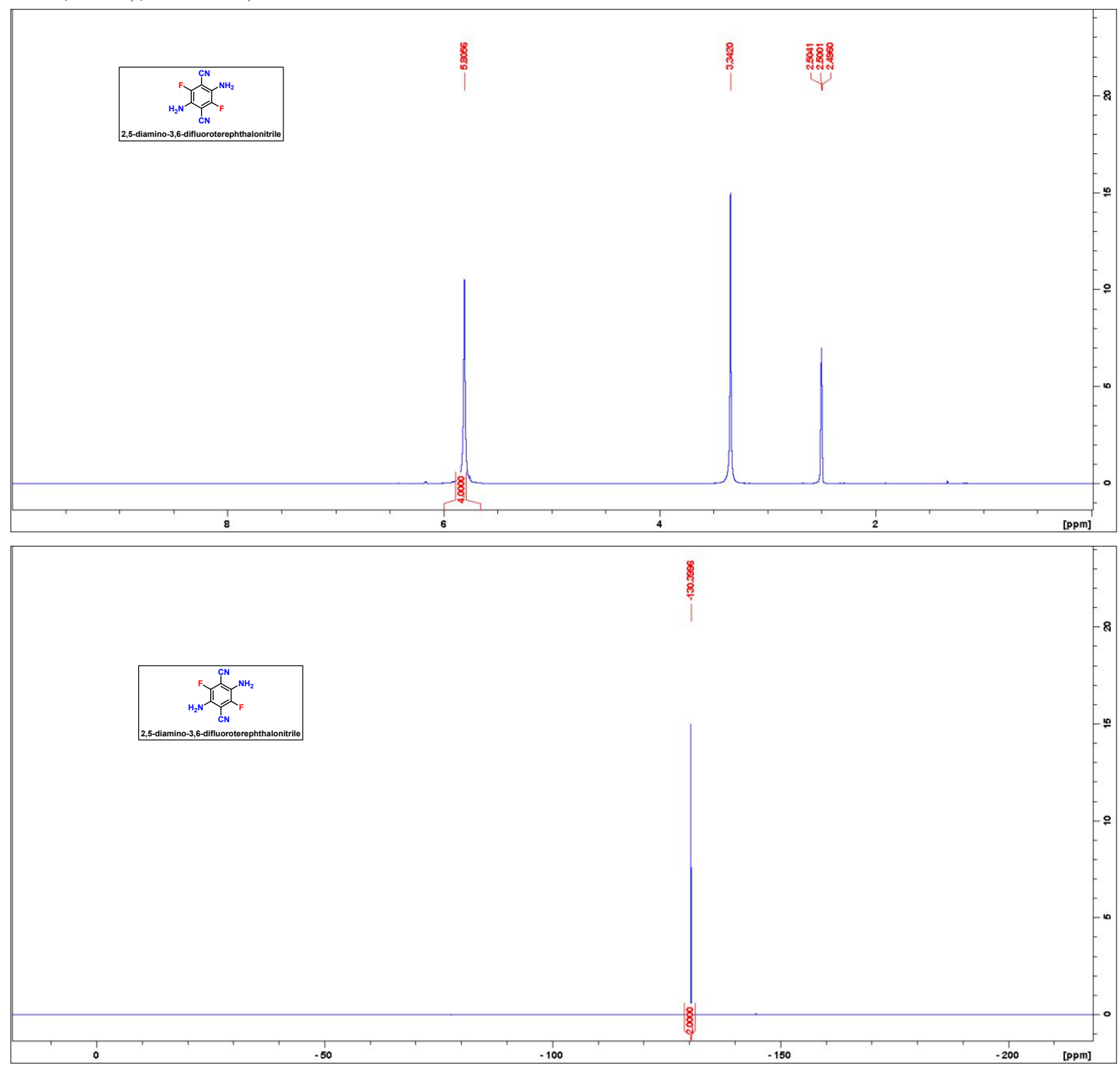

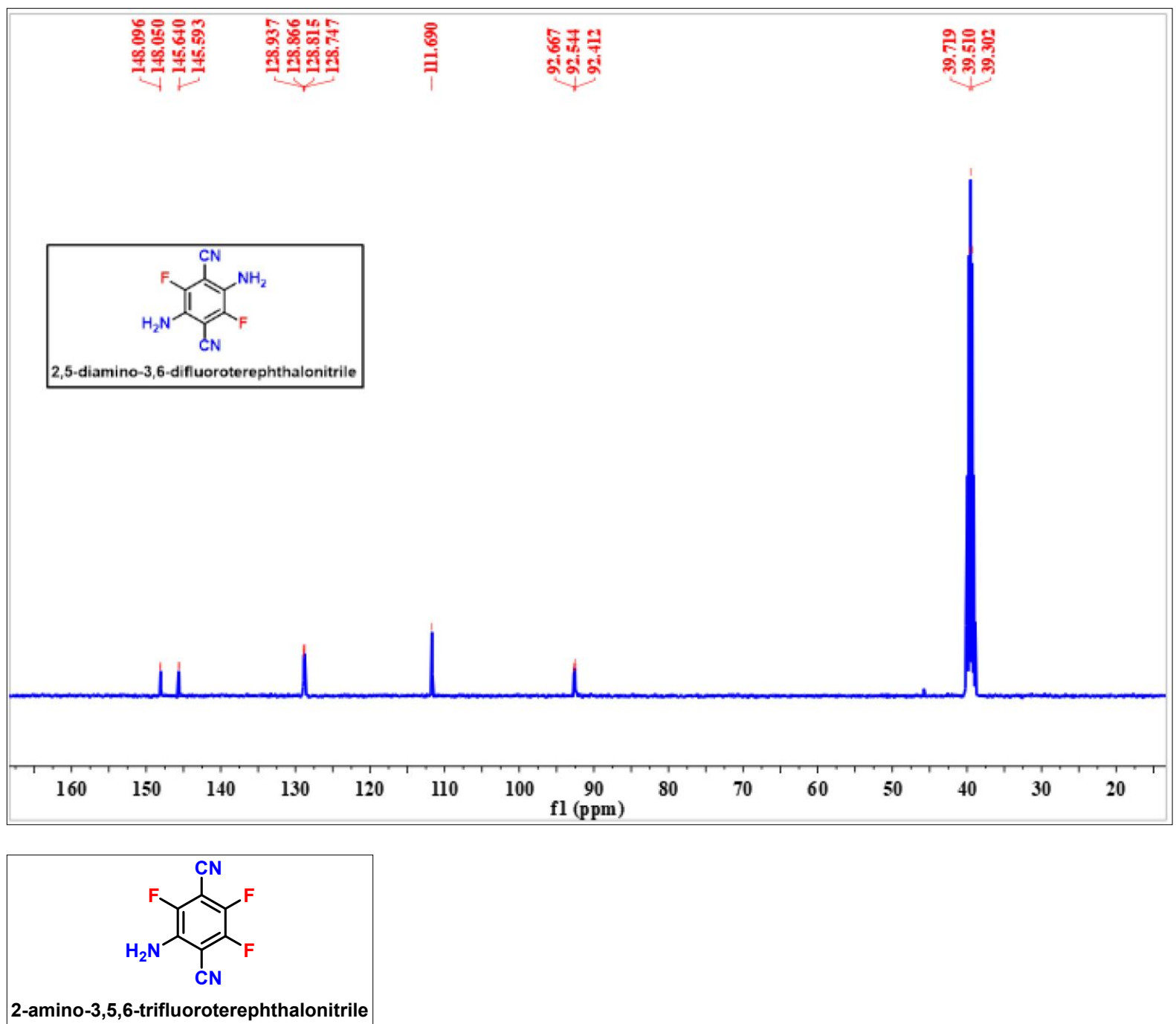

The title compound was prepared by following modified literature procedure: ${ }^{1}$ 2,3,5,6-tetrafluoro1,4-dicyanobenzene (500 mg, 2.5 $\mathrm{mmol}$ ) was dissolved in DMSO and an excess aqueous ammonia $(10 \mathrm{ml})$ was added in one portion. The reaction mixture was allowed to stir at $60^{\circ} \mathrm{C}$ until the starting material has disappeared as judged by TLC and ${ }^{19} \mathrm{~F}$ NMR analysis of the reaction aliquot. Reaction mixture was poured into water under vigorous stirring and the precipitated product was filtered, washed with water and vacuum dried, affording $400 \mathrm{mg}$ of light yellow solid. ${ }^{1} \mathrm{H}$ and ${ }^{19} \mathrm{~F}$ NMR spectra were in accord with the literature.

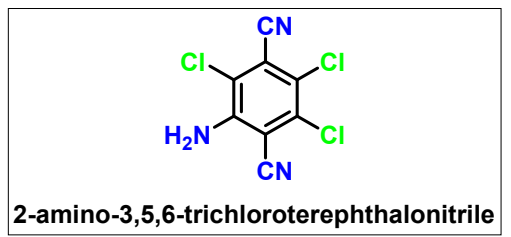

The title compound was prepared in a simple 2-step procedure: 2,3,5,6-tetrachloro-1,4-dicyanobenzene (7.98 g, $30 \mathrm{mmol})$ was dissolved in anhydrous DMF $(150 \mathrm{ml})$ and a large excess of tert-butylamine $(11 \mathrm{~g}, 150 \mathrm{mmol})$ was added to the solution in one portion. The reaction mixture was allowed to stir at $50{ }^{\circ} \mathrm{C}$ until the starting material has disappeared as judged by TLC analysis of the reaction mixture. Reaction mixture was poured into water under vigorous stirring and the precipitated product was filtered, washed with water and air dried. The obtained intermediate was dissolved in dichloromethane ( $400 \mathrm{ml})$ and excess of TfOH ( $30 \mathrm{~g}$, $200 \mathrm{mmol}$ ) was carefully added causing the formation of a separate liquid layer on the bottom of the flask. After $4 \mathrm{~h}$, the liquid layer at the bottom of the flask was separated using separatory funnel and transferred into a separate $500 \mathrm{ml}$ round bottom flask. Water $(300 \mathrm{ml})$ was added followed by excess amount of $\mathrm{Et}_{3} \mathrm{~N}(30 \mathrm{~g}, 300 \mathrm{mmol})$. The precipitated light-yellow solid was filtered off, washed with water and vacuum dried, affording the title product $(5.6 \mathrm{~g})$ in $75 \%$ overall yield. ${ }^{1} \mathrm{H}$ NMR (400 MHz, DMSO- $\left.d_{6}\right) 7.27$ (s, 2H). ${ }^{13} \mathrm{C}$ NMR (100 MHz, DMSO- $\left.d_{6}\right) 149.0,134.7,122.6,119.8,118.9,114.5,114.2,100.5$. 

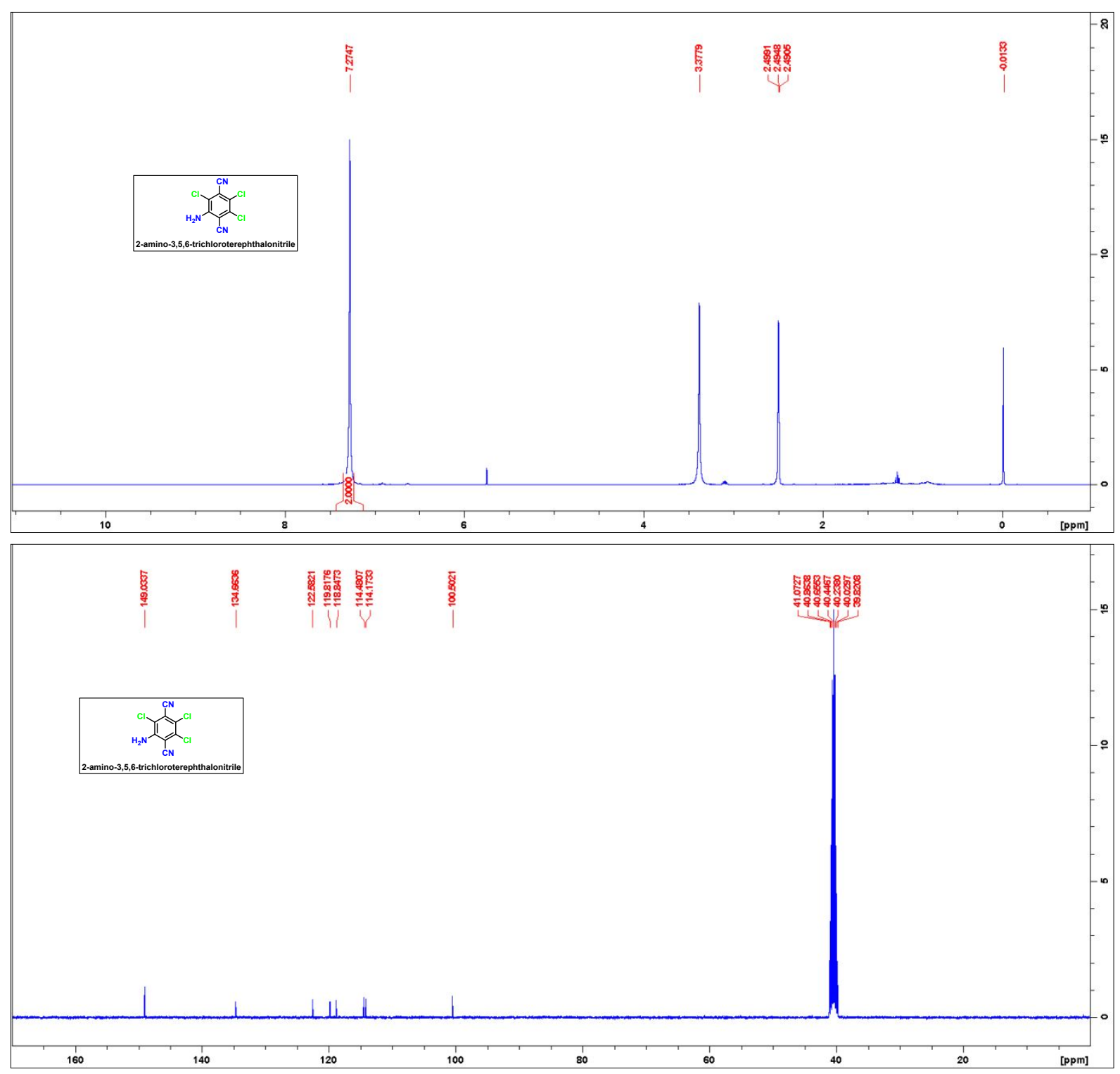

5. Synthesis of the model compound fluorinated tricycloquinazoline (m-F-TCQ)

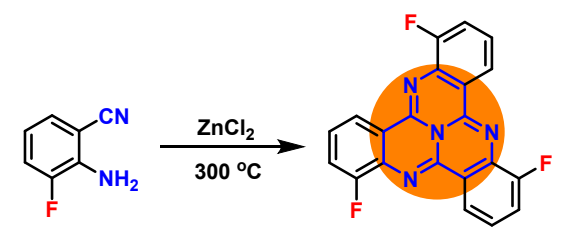

2-amino-3-fluorobenzonitrile

1,6,11-trifluoro-4b1,5,10,15tetraazanaphtho[1,2,3-gh]tetraphene (m-F-TCQ)

A mixture of 2-amino-3-fluorobenzonitrile $(0.136 \mathrm{~g}, 1 \mathrm{mmol})$ and anhydrous $\mathrm{ZnCl}_{2}(0.136 \mathrm{~g}, 1 \mathrm{mmol})$ was vacuum-sealed in a Pyrex ampoule, and then heated at $200{ }^{\circ} \mathrm{C}$ for $24 \mathrm{~h}$ in a muffle furnace with a ramping rate of $5{ }^{\circ} \mathrm{C} / \mathrm{min}$. The obtained mixture was washed thoroughly with dilute $\mathrm{HCl}$, water, and methanol to afford the pure product. The solid product was then dried in a vacuum oven at $120^{\circ} \mathrm{C}$ for $24 \mathrm{~h}$ and the yield was calculated to be $73 \%$. The product was solubilized in trifluroracetic acid-d (TFA-d) for NMR and ESI-MS characterization (Figure S1). ${ }^{1} \mathrm{H}$ NMR (400 MHz, TFA-d) 8.67-8.57 (m, 3H), 7.85-7.74 (m, 6H). ${ }^{19} \mathrm{~F}$ NMR (376 MHz, TFA- $d$ ) -126.46 (s, 3F). ${ }^{13} \mathrm{C}$ NMR (100 MHz, TFA- $d$ ) $155.3\left(\mathrm{~d}, J_{C-F}=258.8 \mathrm{~Hz}\right), 143.6\left(\mathrm{~d}, J_{C-F}=2.5 \mathrm{~Hz}\right), 130.7\left(\mathrm{~d}, J_{C-F}=7.7\right.$ $\mathrm{Hz}), 129.9\left(\mathrm{~d}, J_{C-F}=13.7 \mathrm{~Hz}\right), 122.5\left(\mathrm{~d}, J_{C-F}=18.2 \mathrm{~Hz}\right), 121.6\left(\mathrm{~d}, J_{C-F}=4.3 \mathrm{~Hz}\right), 117.6$.

\section{Fabrication of F-CQNs}


Notes: Volatile products, potentially $\mathrm{CF}_{4}, \mathrm{C}_{2} \mathrm{~F}_{4}$ and $\mathrm{F}_{2}$, are produced during the reaction. After cooling down to room temperature, the quartz tube must be immersed in liquid nitrogen for $\sim 10 \mathrm{~min}$, and then opened carefully in the hood.

F-CQNs materials were synthesized by $\mathrm{ZnCl}_{2}$-catalyzed ionothermal method according to the previous literature with some modifications (O. Buyukcakir, R. Yuksel, Y. Jiang, S. H. Lee, W. K. Seong, X. Chen and R. S. Ruoff, Angew. Chem. Int. Ed., 2019, 58, 872-876.). Typically, the synthesis of F-CQN-1-600 was shown as the following: A mixture of 2,5-diamino-3,6-difluoroterephthalonitrile $(0.6 \mathrm{mmol})$ and $\mathrm{ZnCl}_{2}(6.0 \mathrm{mmol}$, molar ratio of 1:10) was vacuum-sealed in a quartz tube, and then heated at $600{ }^{\circ} \mathrm{C}$ for $24 \mathrm{~h}$ in a muffle furnace with a ramping rate of $5{ }^{\circ} \mathrm{C} / \mathrm{min}$. The obtained black powder was subsequently ground and washed thoroughly with dilute $\mathrm{HCl}$, water, THF and acetone. The material was then dried in a vacuum oven at $120^{\circ} \mathrm{C}$ for $24 \mathrm{~h}$ before characterization and battery test.

F-CQN-1-200, F-CQN-1-300, F-CQN-1-400, F-CQN-1-500, and F-CQN-1-700, was prepared at the target temperature $\left(200^{\circ} \mathrm{C}\right.$, $300{ }^{\circ} \mathrm{C}, 400{ }^{\circ} \mathrm{C}, 500{ }^{\circ} \mathrm{C}$ and $700{ }^{\circ} \mathrm{C}$ ) for $24 \mathrm{~h}$, respectively.

F-CQN-2-600, F-CTF-1-600, and Cl-CQN-2-600 were prepared using the corresponding monomers, the molar ratio of nitrile monomer: $\mathrm{ZnCl}_{2}$ is $1: 10$ and the reaction temperature is $600{ }^{\circ} \mathrm{C}$.

\section{Supplementary figures and contents}
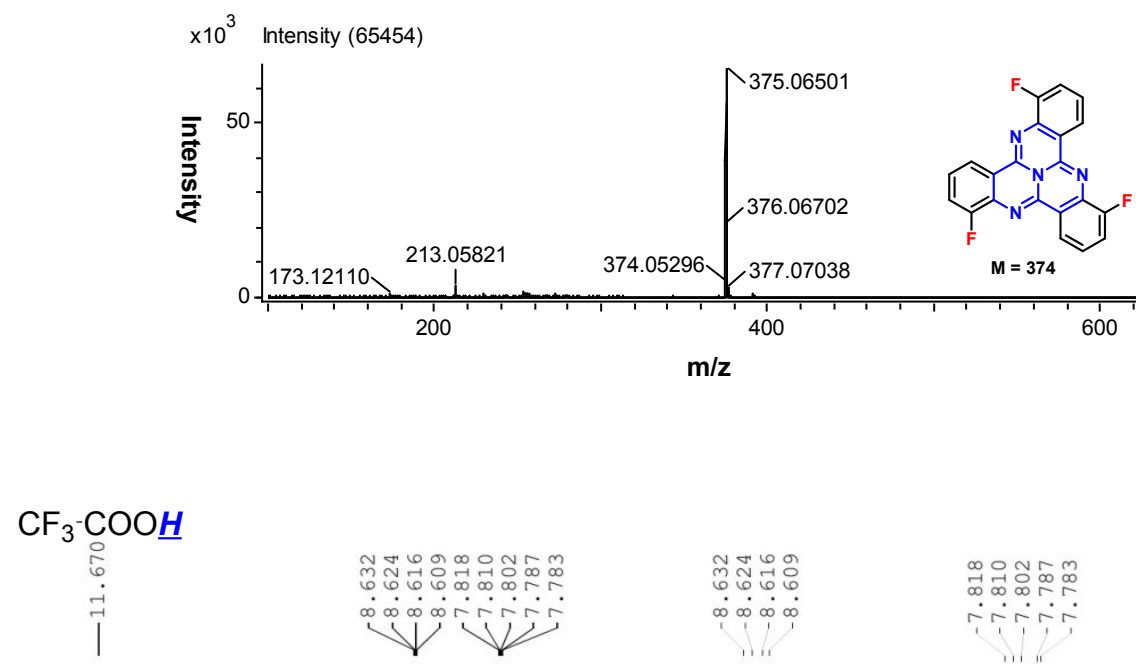

${ }^{1} \mathrm{H}$ NMR (TFA-d, $400 \mathrm{MHz}$ )

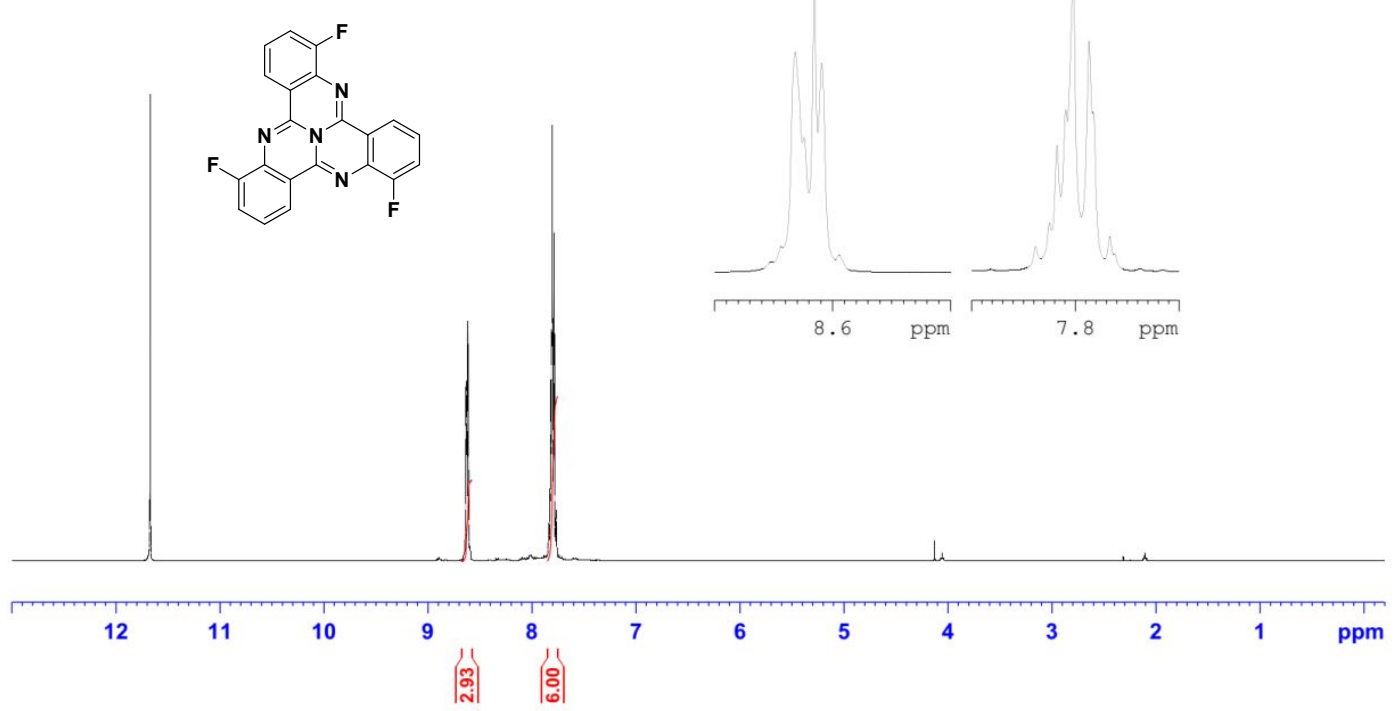



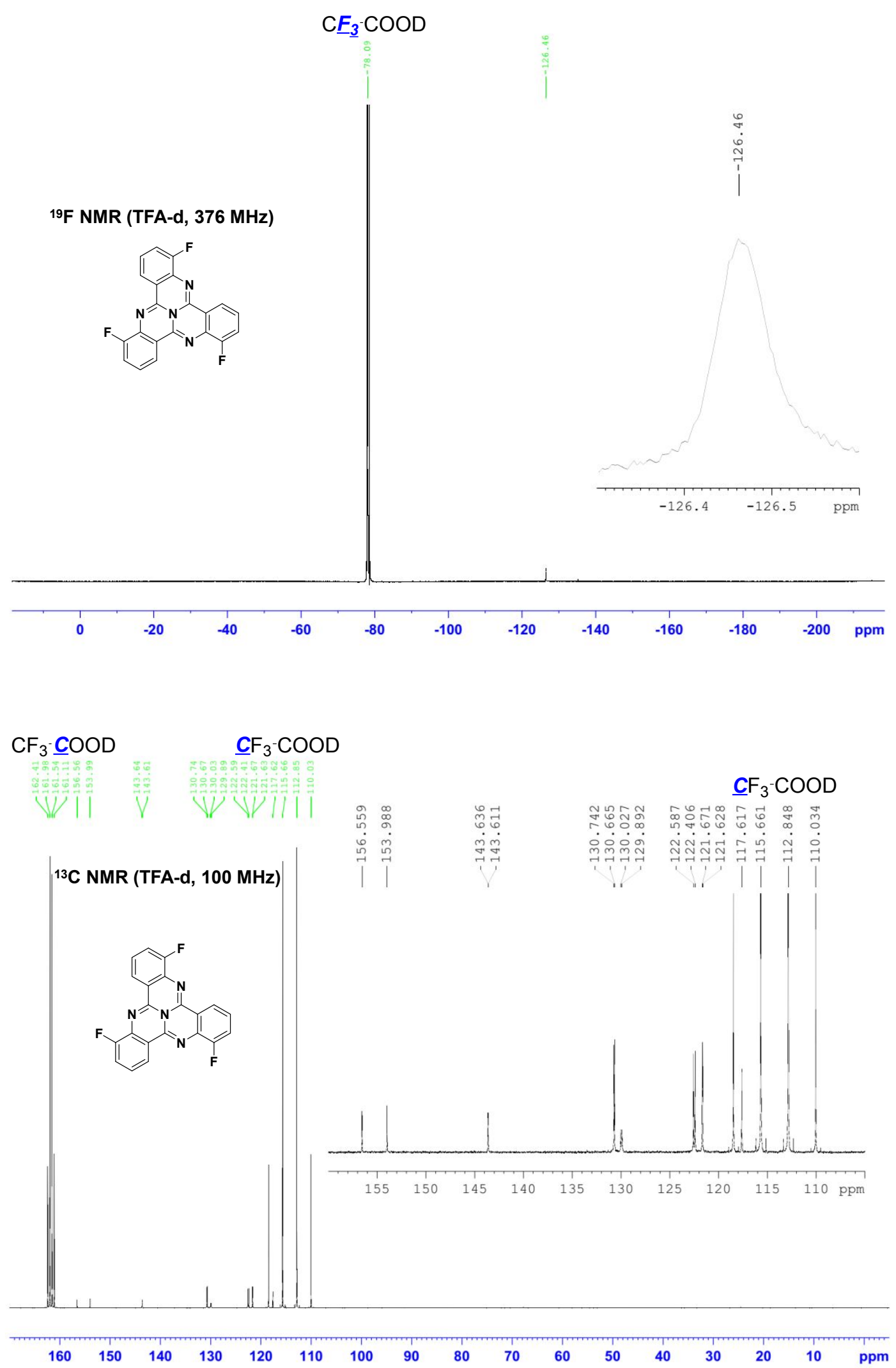

Figure S1 ESI-MS spectrum and ${ }^{1} \mathrm{H},{ }^{19} \mathrm{~F},{ }^{13} \mathrm{C}$ NMR spectra of m-F-TCQ. 
The NMR spectra support the C3-symmetric structure of the product. Proton NMR clearly indicated 2 regions with the expected integral ratios and the expected splitting pattern originating from the presence of fluorine atoms and hydrogens. Fluorine NMR spectrum clearly indicates the presence of only 1 peak in the expected aromatic region appearing as a singlet, this is consistent with 3 equivalent fluorine atoms being present in the $\mathrm{C} 3$-symmetric structure. Carbon NMR spectrum shows the presence of signals corresponding to signals of only 7 nonequivalent carbon atoms, i.e. m-F-TCQ has 21 total carbons and due to C3 molecular symmetry only 7 signals are expected with each signal corresponding to 3 equivalent carbon atoms. These carbon signals have different degrees of splitting and the J coupling constants. Additional 8 signals present in the carbon NMR spectrum are coming from 2 regions in which $\mathrm{CF}_{3} \mathrm{COOD}$ NMR solvent signals appear as quartets with large coupling constants, as would be expected due to the presence of fluorine atoms. Taken together with the mass spectrometric characterization providing unequivocal confirmation of the molecular weight of the $\mathrm{M}+\mathrm{H}$ ( $\mathrm{m} / \mathrm{Z}$ to be precise), all NMR characterization data are consistent with and supportive of the presented m-F-TCQ molecular structure.
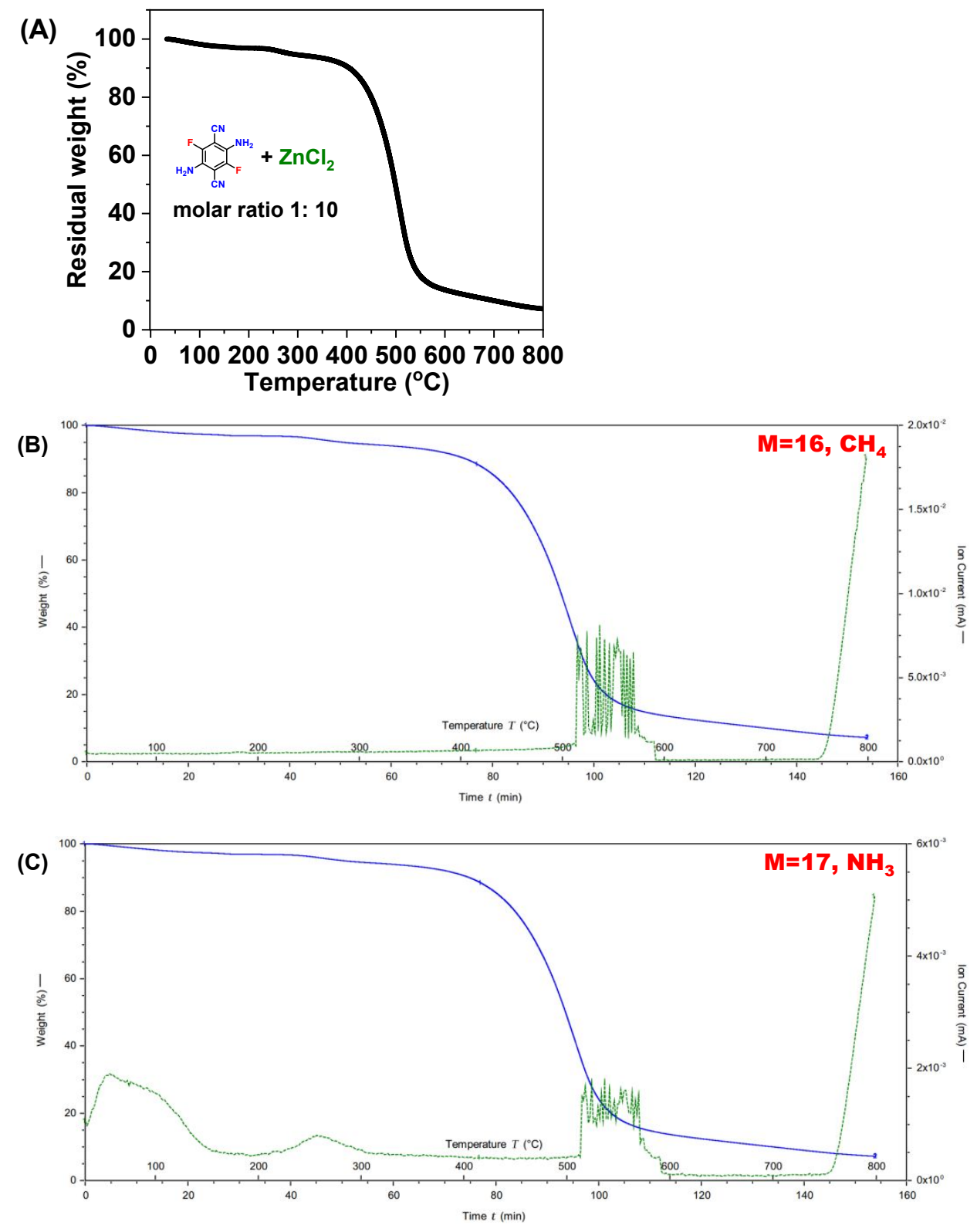

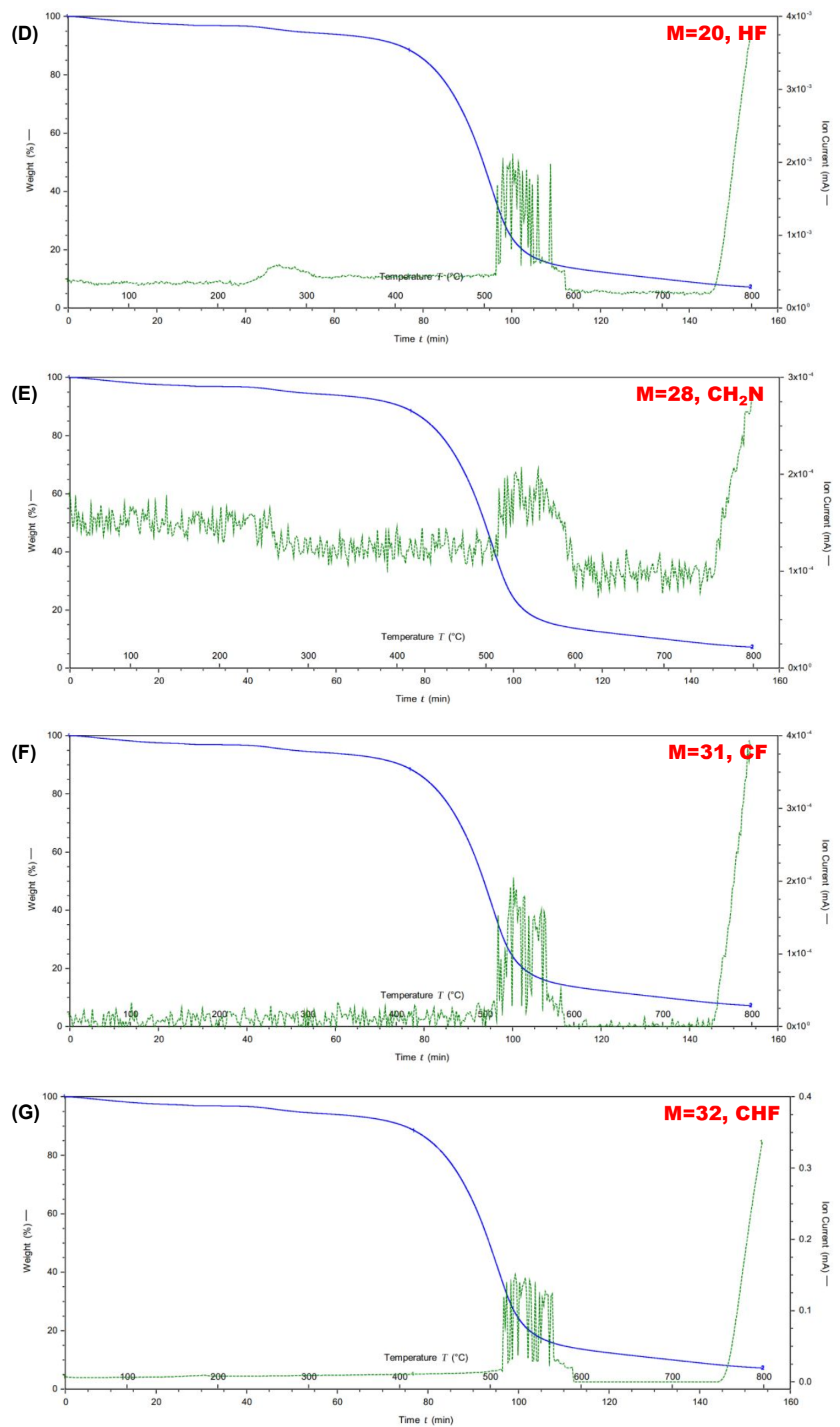

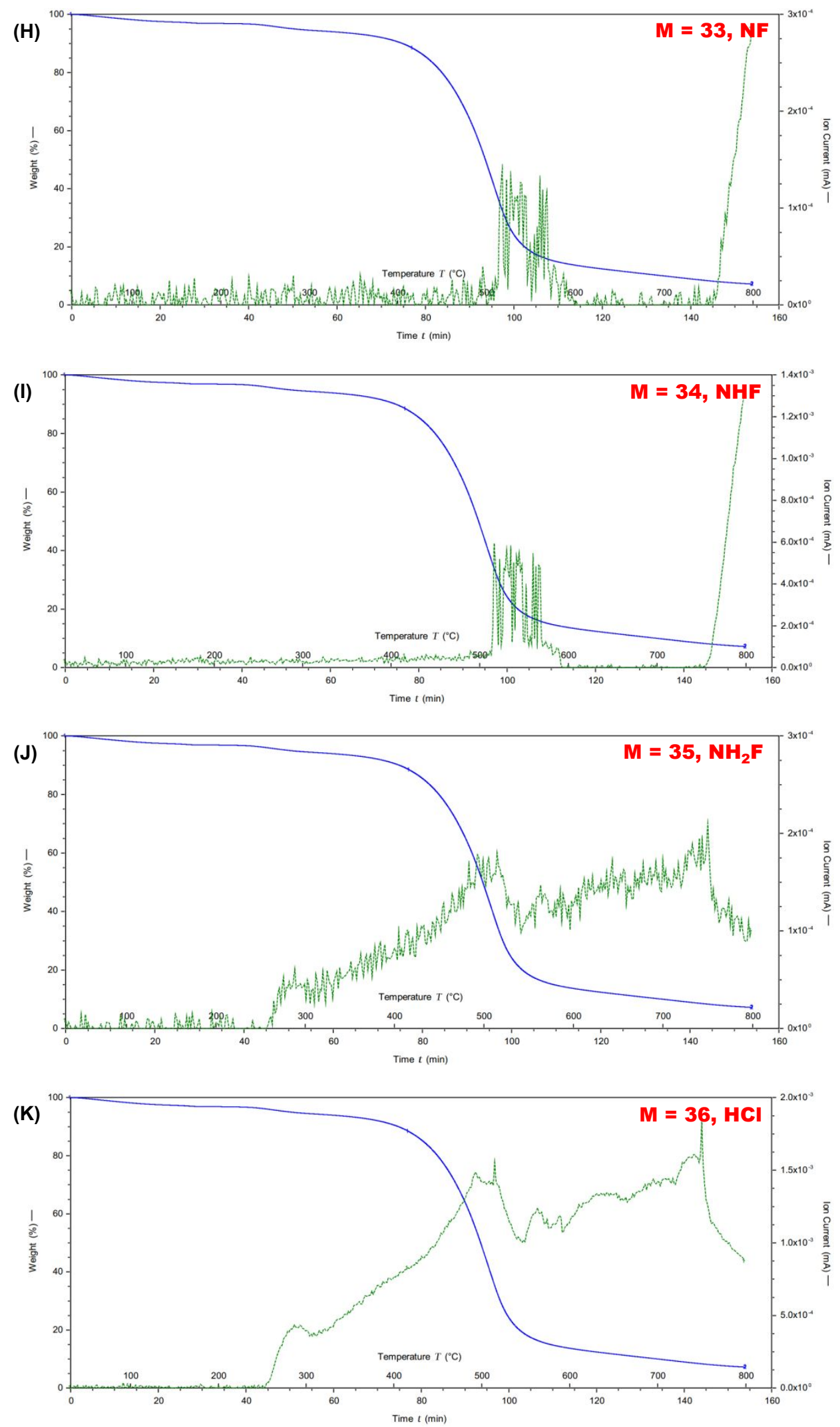

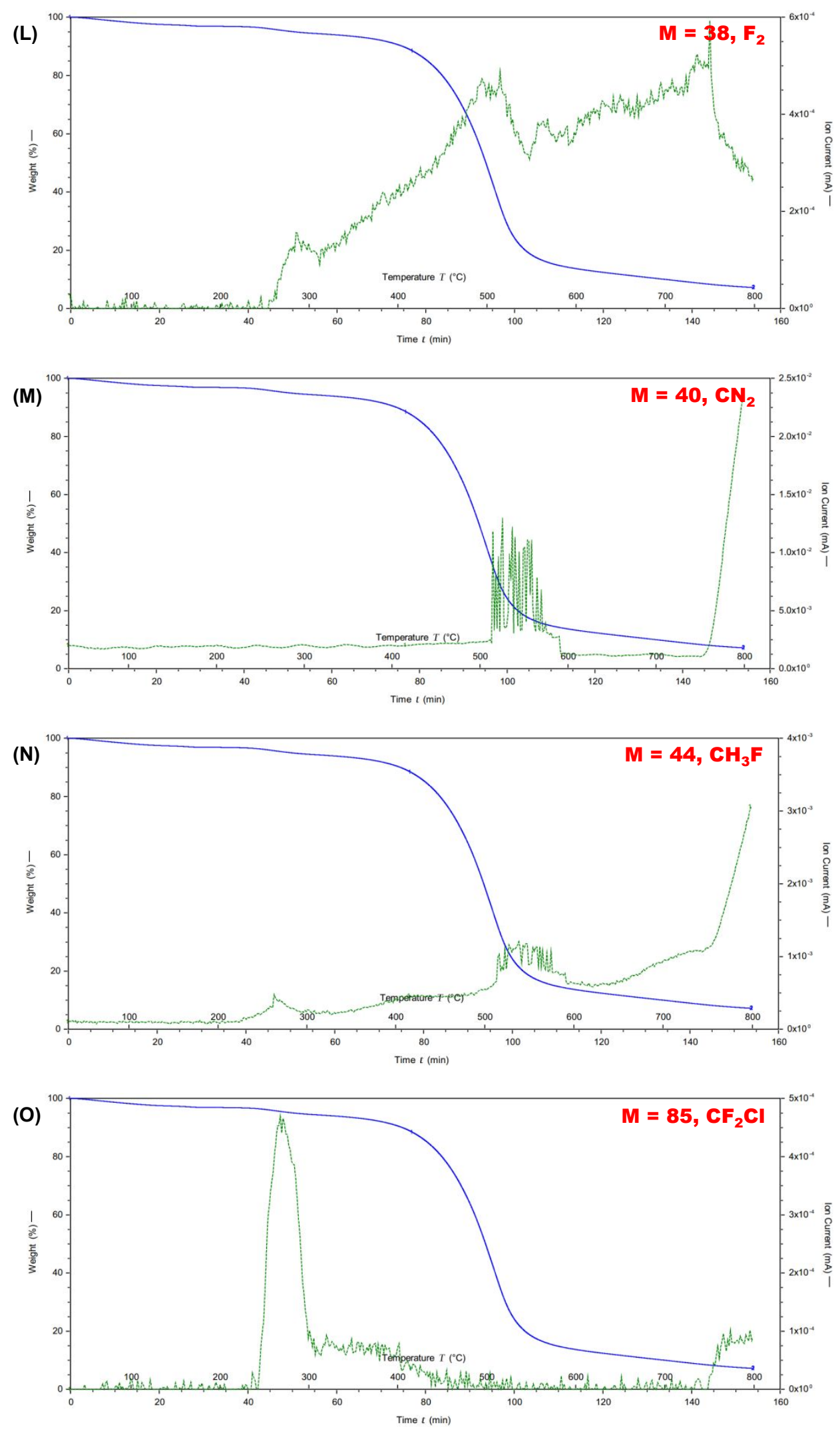

Figure S2 (A) TGA result of the mixture composed of 2,5-diamino-3,6-difluoroterephthalonitrile and $\mathrm{ZnCl}_{2}$ (molar ratio 1: 10 , same as that used for F-CQNs synthesis) under $\mathrm{N}_{2}$ atmosphere in the range of $25 \sim 800{ }^{\circ} \mathrm{C}$ with a ramping rate of $5{ }^{\circ} \mathrm{C} \min ^{-1}$. (B O) Molecular weight, structure, and curves of different gaseous products formed along with the time and heating temperature. 

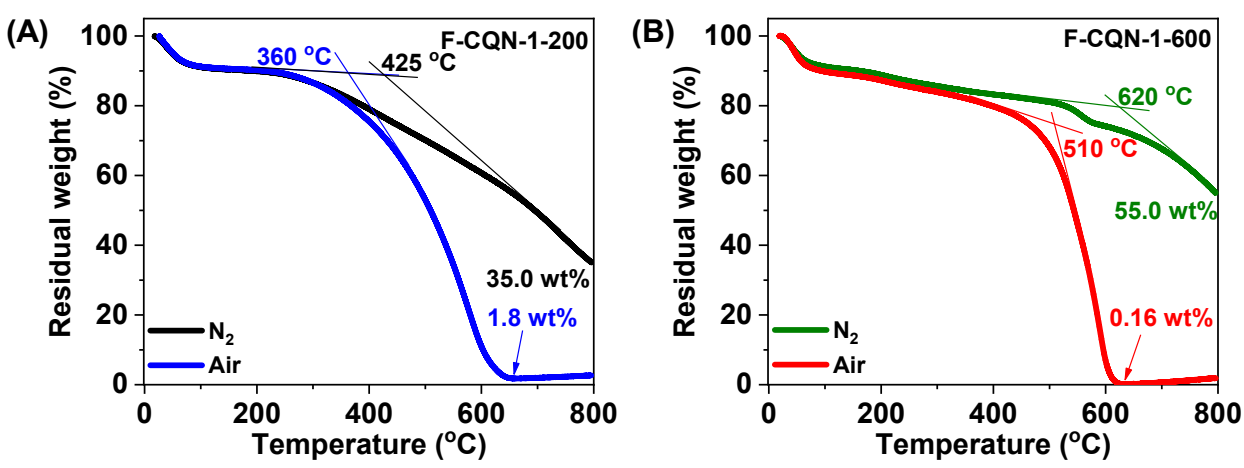

Figure S3 TGA results of F-CQN-1-200 and F-CQN-1-600 under nitrogen and air atomosphere from 25 to $800{ }^{\circ} \mathrm{C}$ with a ramping rate of $10^{\circ} \mathrm{C} \mathrm{min}^{-1}$.

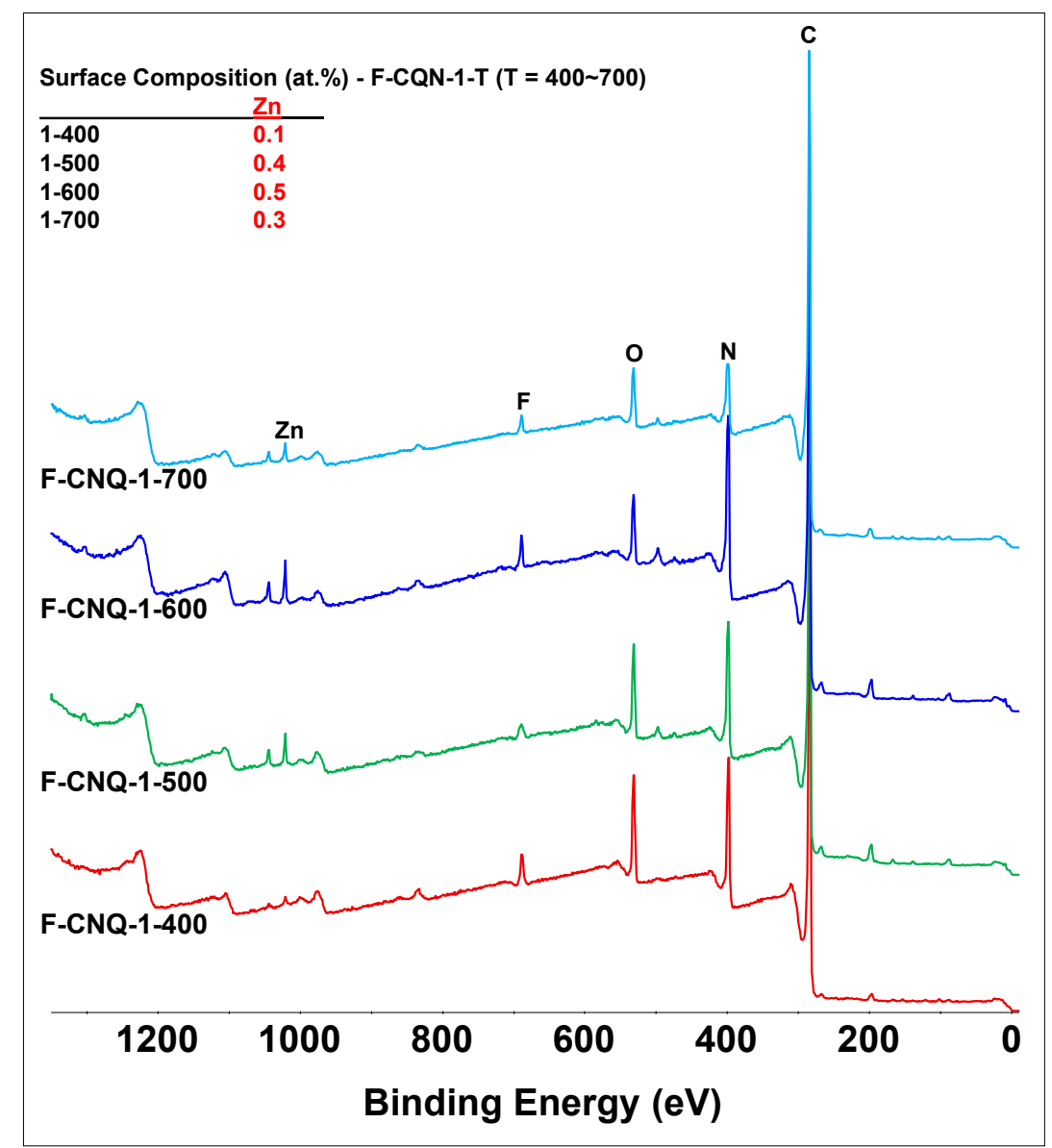

Figure S4 XPS survey spectra of F-CQN-1-400 F-CQN-1-700. 


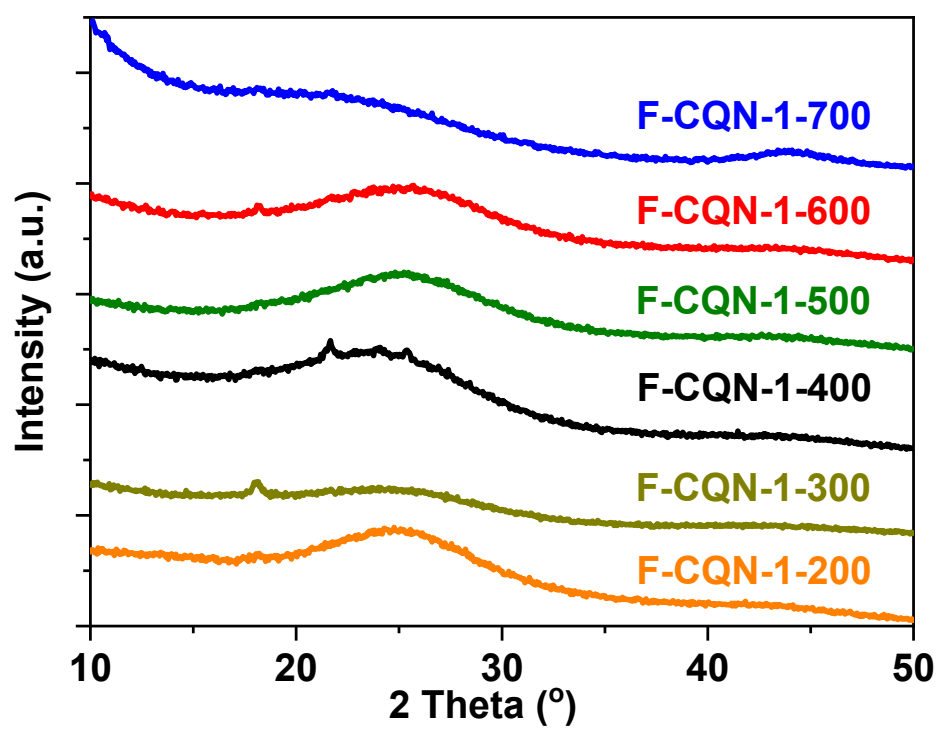

Figure S5 PXRD patterns of F-CQN-1-200 F-CQN-1-700.

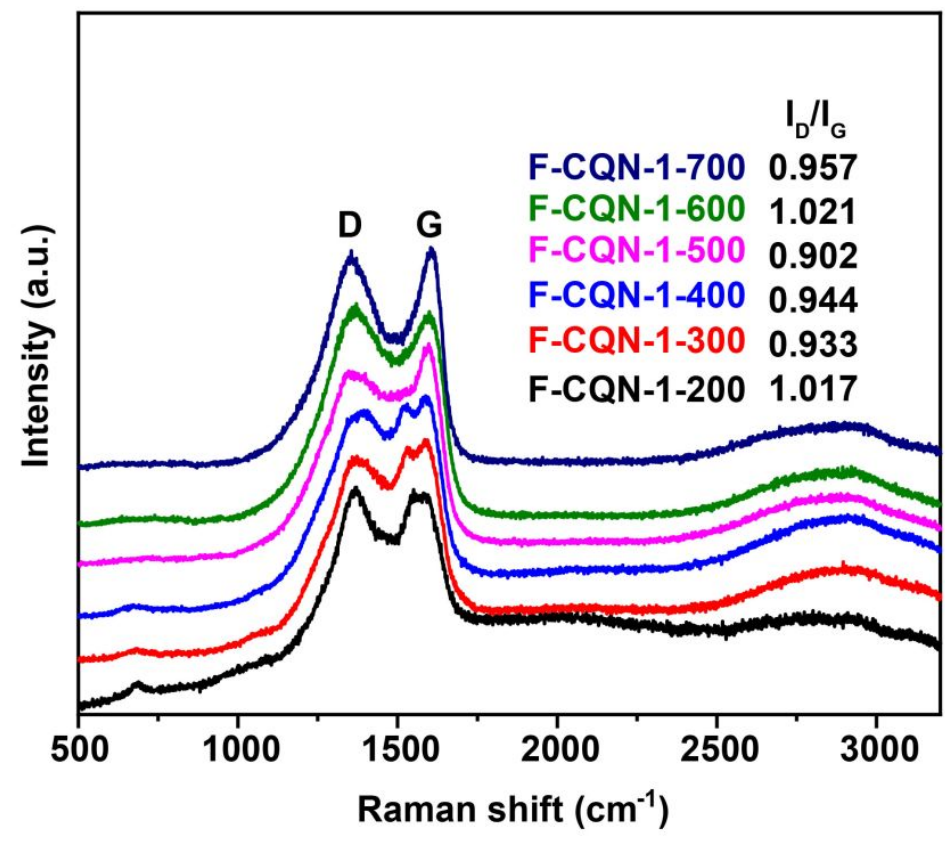

Figure S6 Raman spectra of F-CQN-1-200 F-CQN-1-700. 

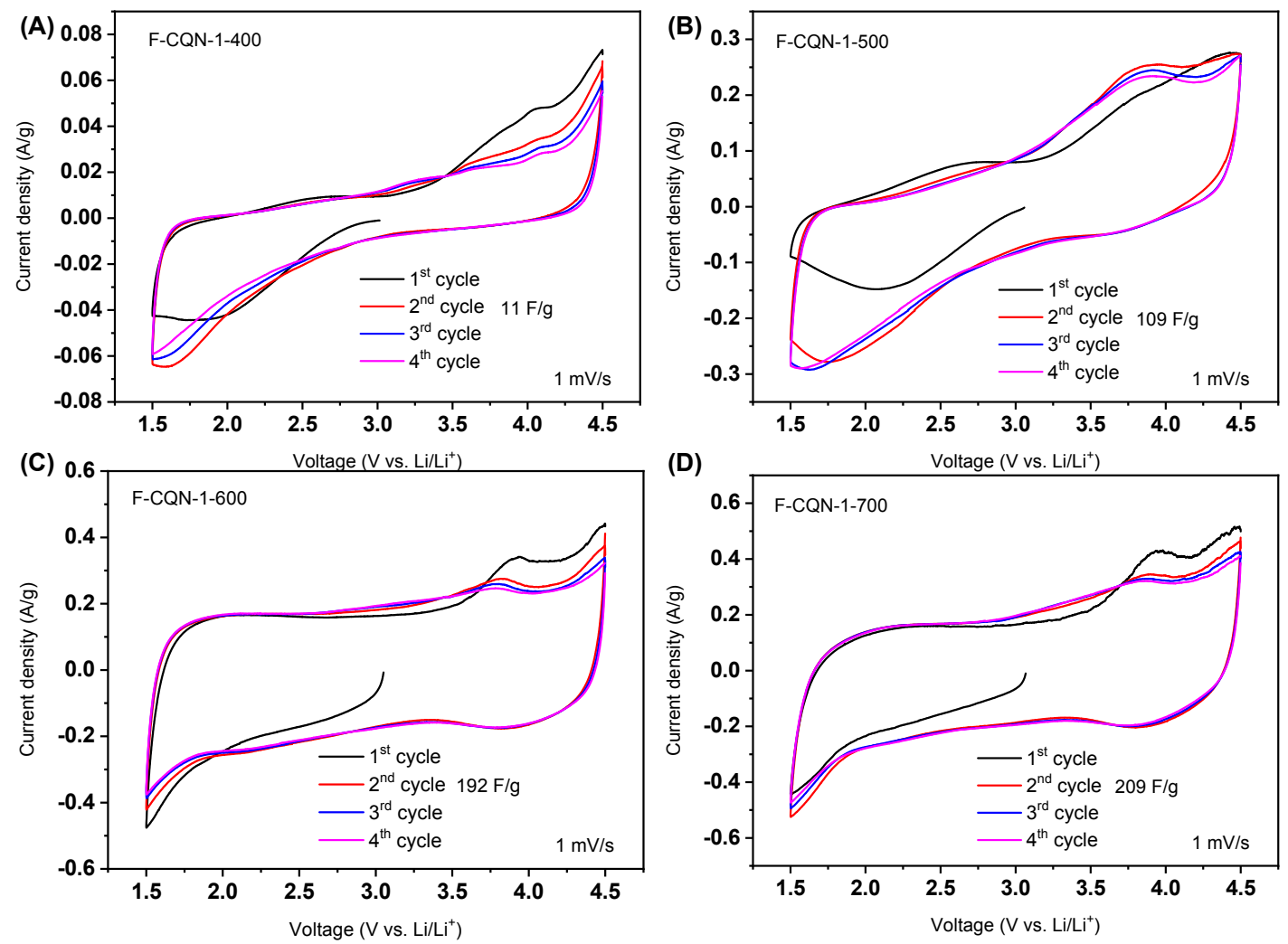

Figure S7 First 4 cycles of CV curves for F-CQN-1-400 F-CQN-1-700. 

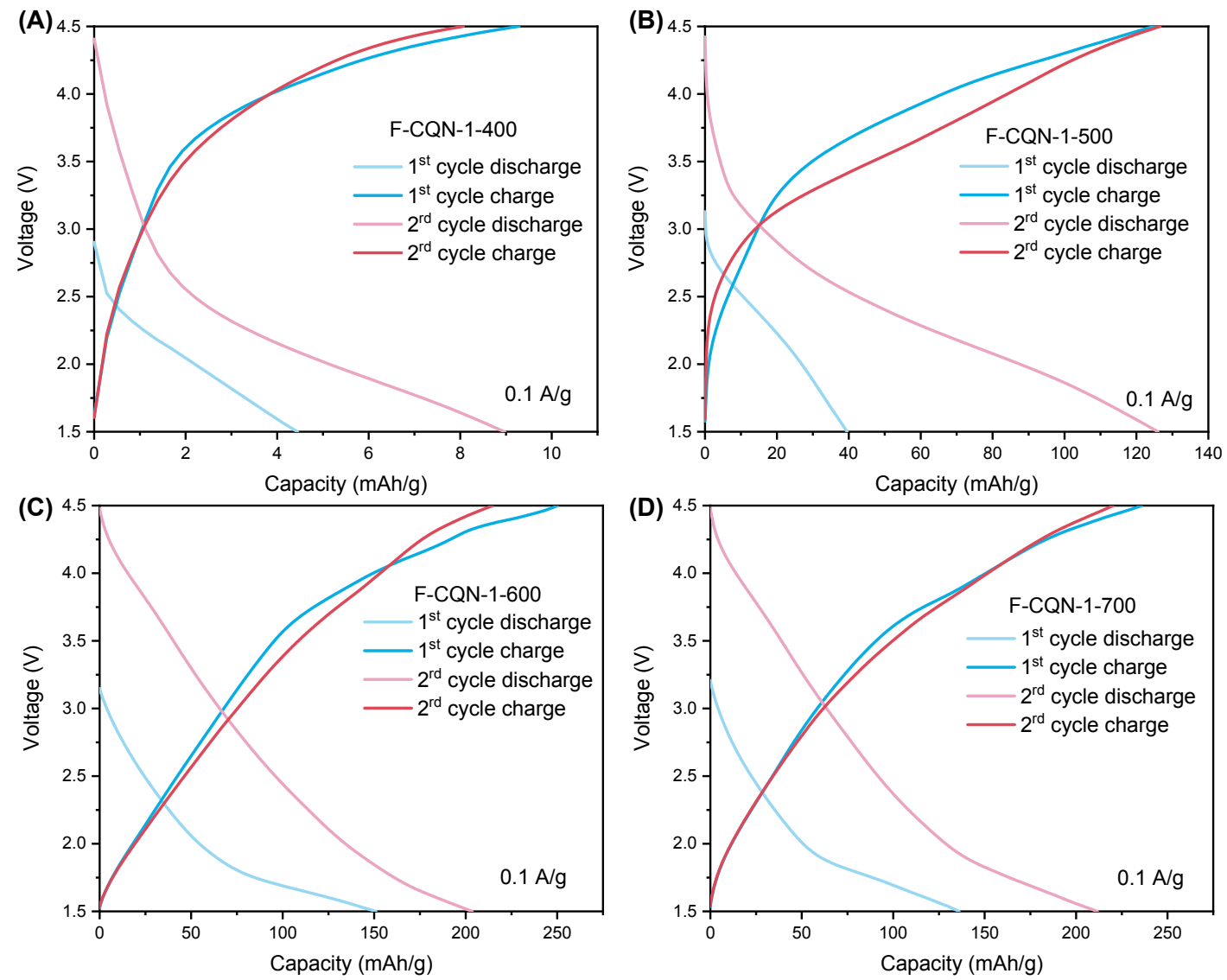

Figure S8 First and second cycle charge/discharge curves of F-CQN-1-400 F-CQN-1-700.
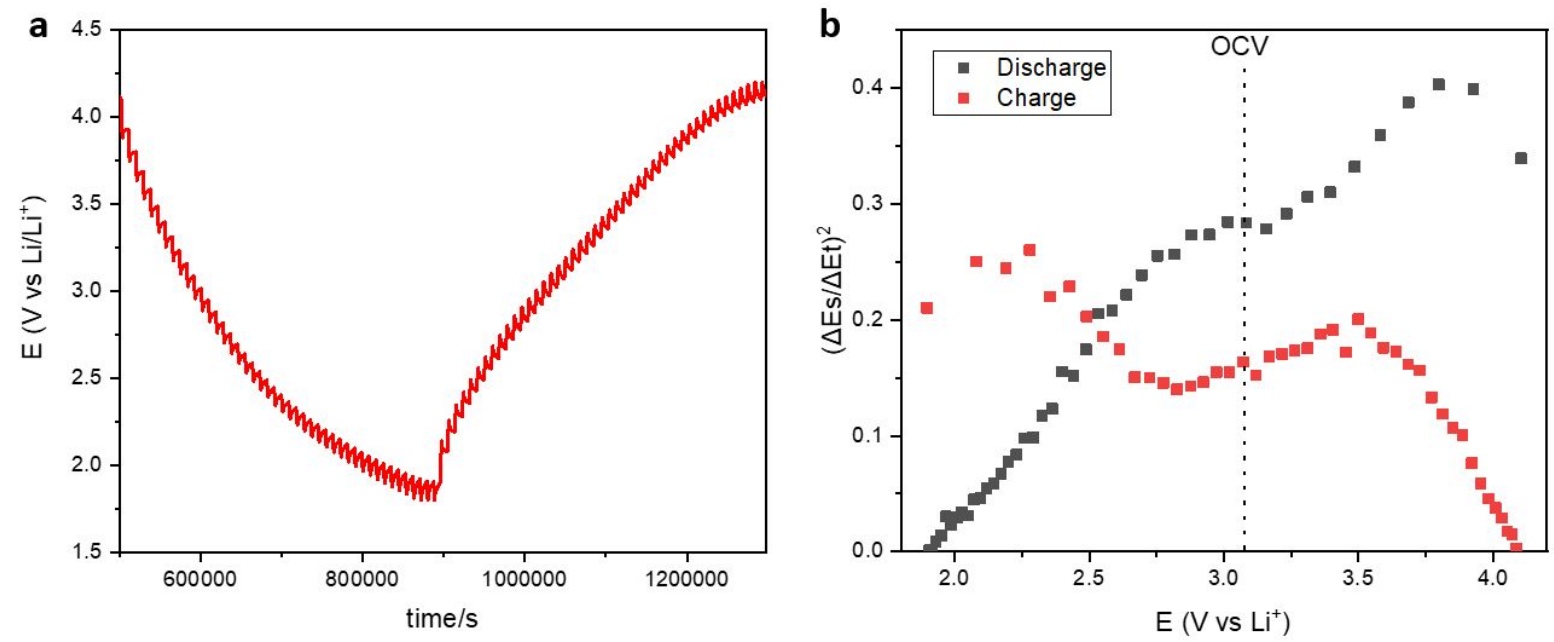

Figure S9 a) GITT curve of F-CQN-1-600 which were acquired with a current flux of $5 \mathrm{~mA} \mathrm{~g}^{-1}$ for 30 min in the potential range of $1.8-4.2 \mathrm{~V}$, followed by resting for $2 \mathrm{~h}$ to reach the steady state; b) The relationship between $\left.\left(\Delta \mathrm{E}_{\mathrm{s}} / \Delta \mathrm{E}_{\tau}\right)^{2}\right)$ and $\mathrm{E}\left(\mathrm{V} \mathrm{vs} \mathrm{Li} / \mathrm{Li}^{+}\right)$. 

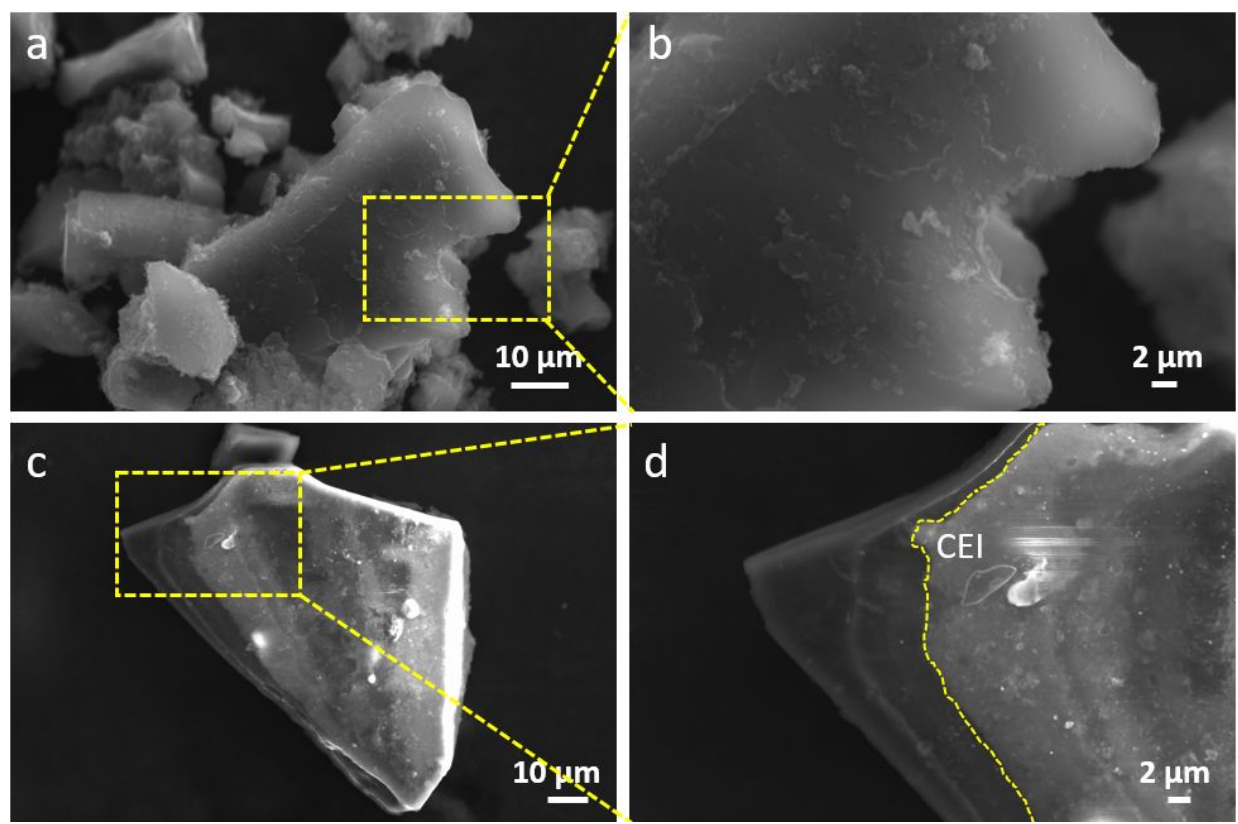

Figure S10 (a) and (b) SEM image of F-CQN-1-600 after cycling; (c) and (d) SEM image of F-CQN-1-700 after cycling.

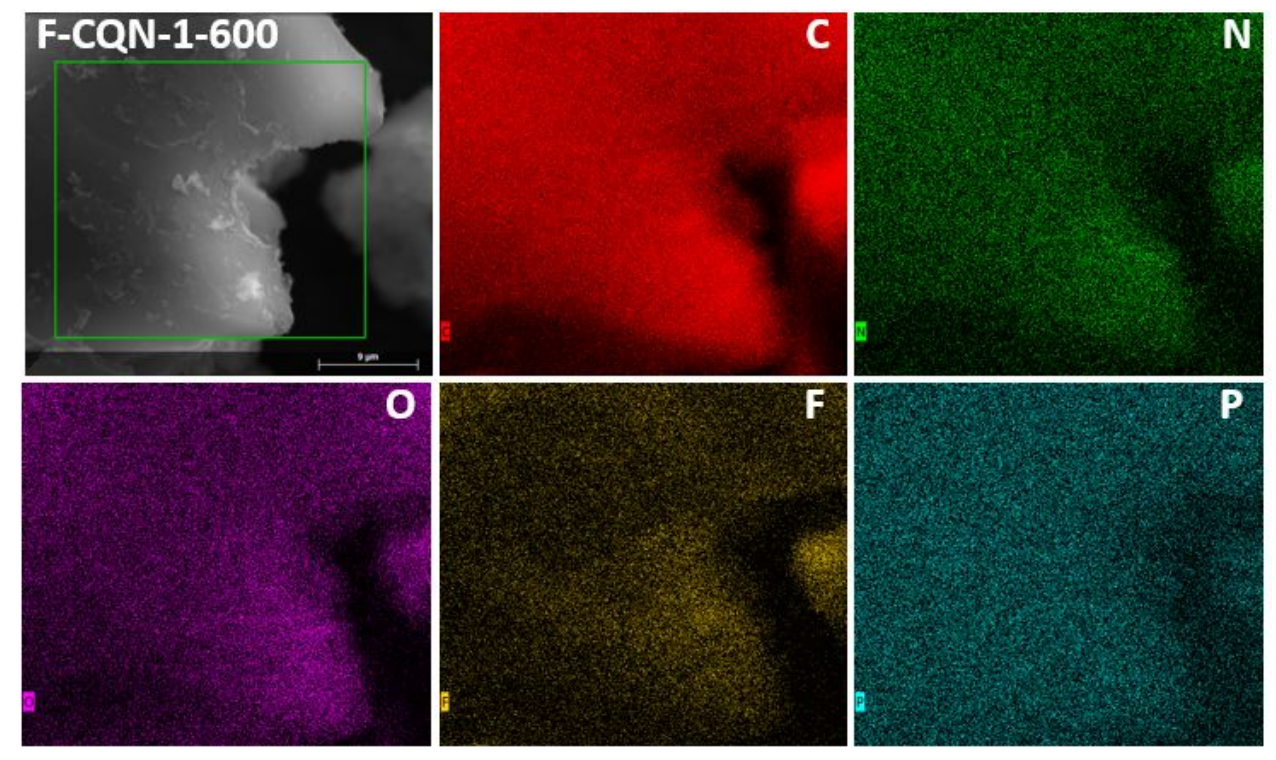

Figure S11 SEM element mapping of F-CQN-1-600 after charging process. 


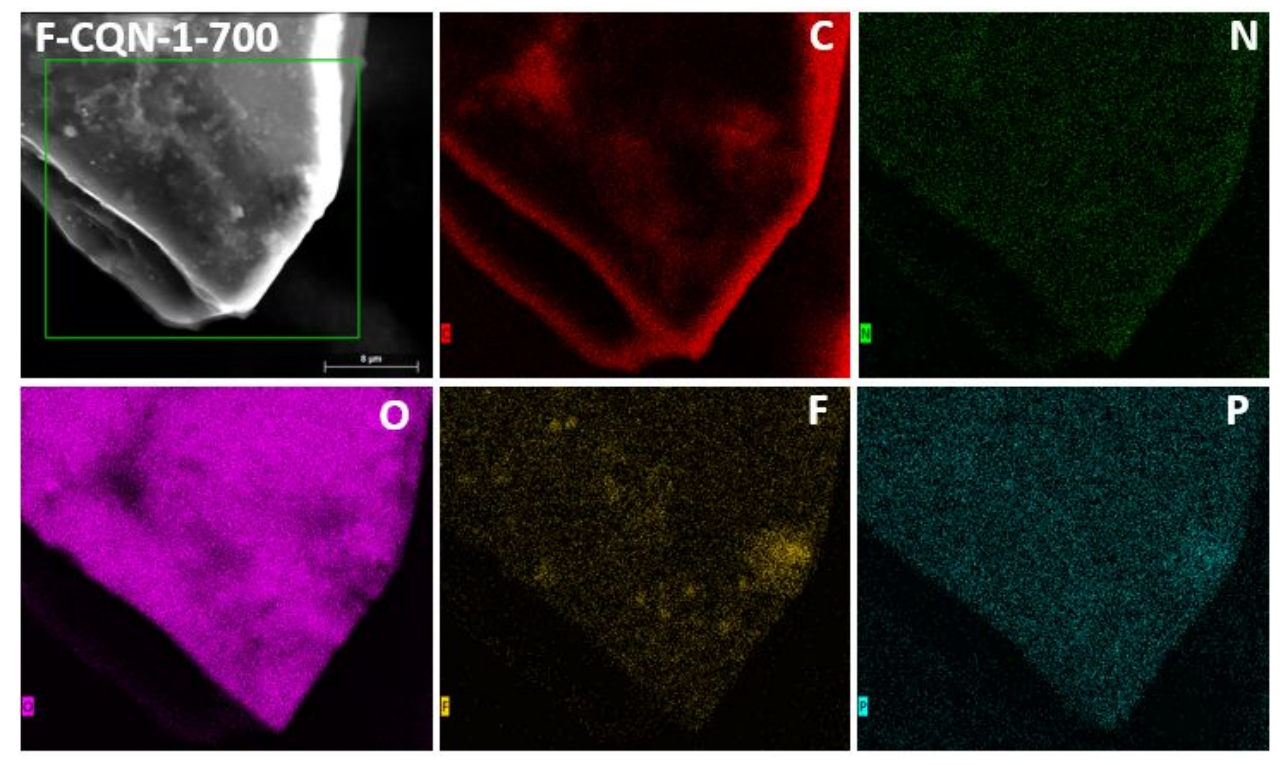

Figure S12 SEM element mapping of F-CQN-1-700 after charging process.
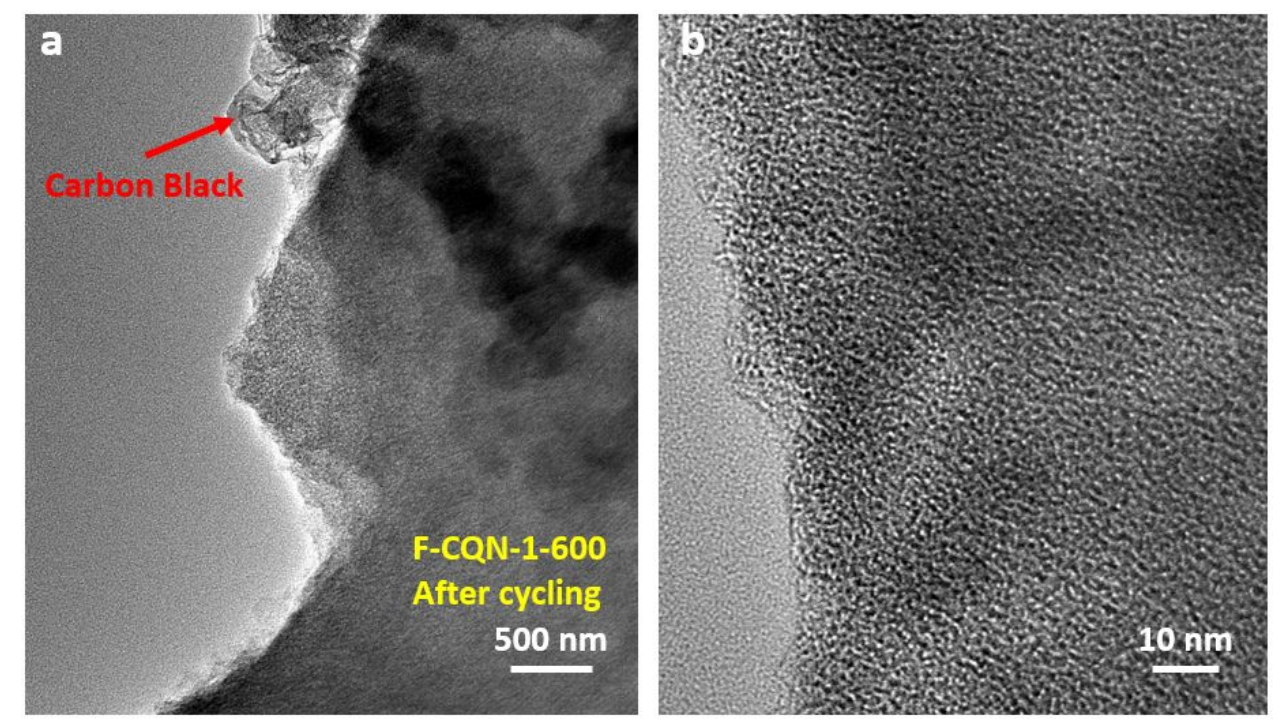

Figure S13 (a) and (b) TEM image of F-CQN-1-600 after cycling. 


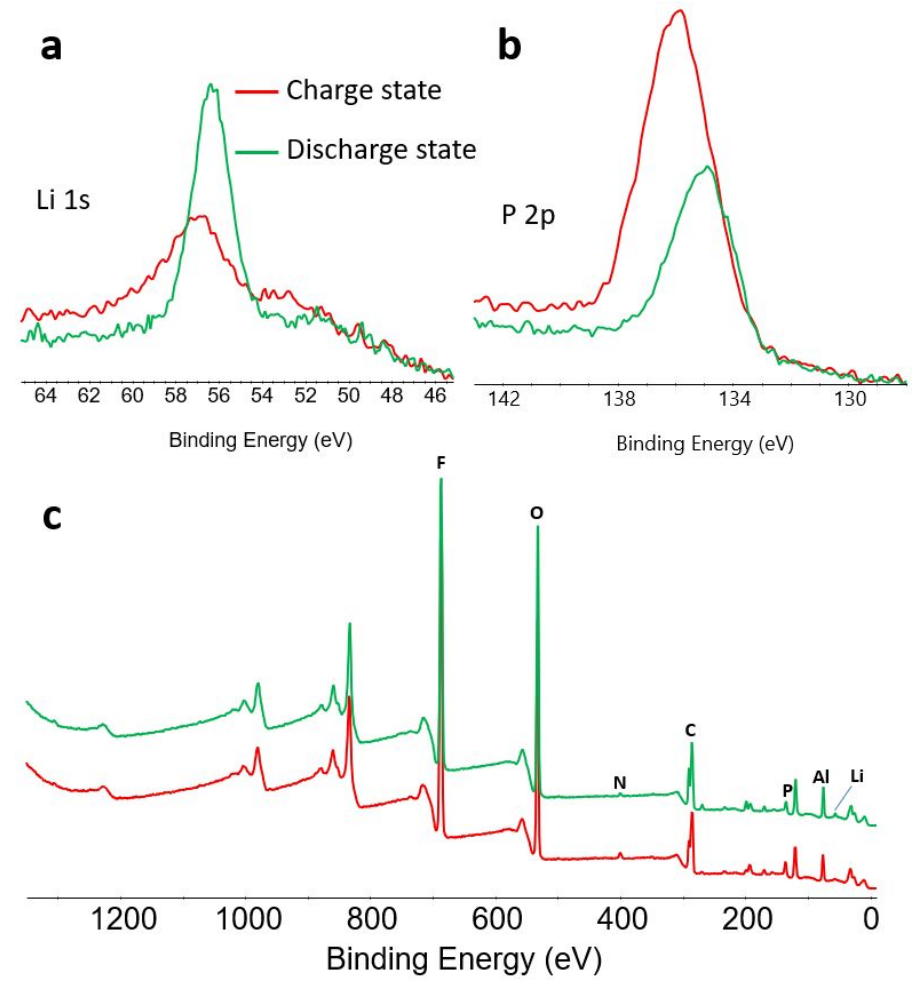

Figure S14. XPS spectra for charged and discharged F-CQN-1-600. a) Li 1s; b) P 2p; c) survey spectra.

Table S1. Surface composition of the charged and discharged F-CQN-1-600 calculated from XPS results.

\begin{tabular}{llllllll}
\hline & $\mathbf{L i}($ at.\%) & $\mathbf{C ~ ( a t . \% )}$ & N (at.\%) & O (at.\%) & P (at.\%) & F (at.\%) & Al (at.\%) \\
\hline Charge state & 6.2 & 25.7 & 1.1 & 22.8 & 2.6 & 30.4 & 10.4 \\
Discharge state & 12.4 & 23.1 & 0.6 & 22.9 & 1.6 & 28.8 & 9.4 \\
\hline
\end{tabular}




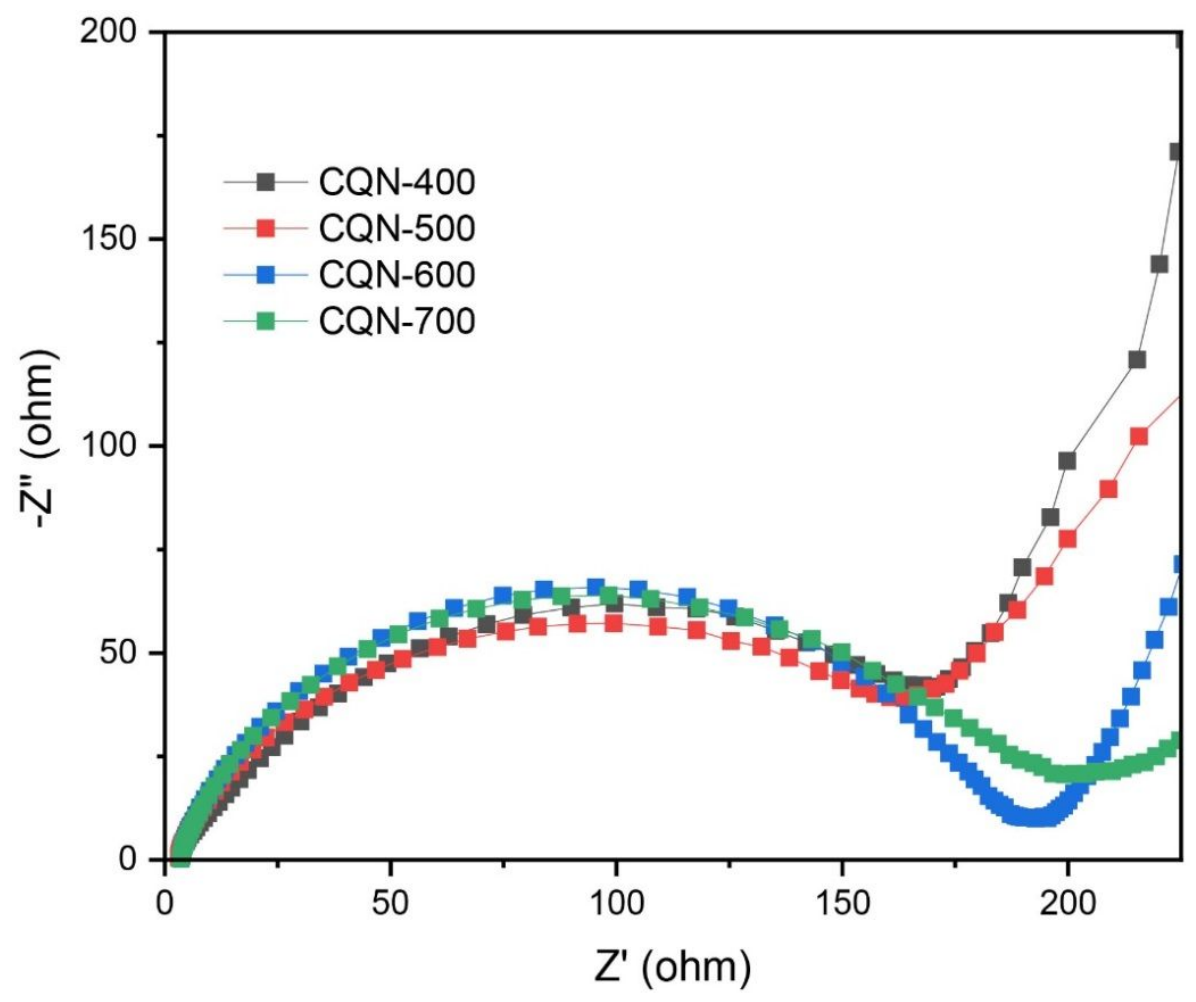

Figure S15 Electrochemical impedance spectra (EIS) of the half-cells at OCV using different active materials for cathodes before cycling.

The nitrogen content slightly decreased in the order of F-CQN-1-400 (28.63 wt $\%)>$ F-CQN-1-500 (26.82 wt $\%)>$ F-CQN-1-600 (23.49 $\mathrm{wt} \%$ ), but sharply decreased to $13.53 \mathrm{wt} \%$ in F-CQN-1-700. EIS of F-CQNs derived from different heating temperatures were tested under the similar experimental condition before cycling, which are used to compare their relevant conductivities. The semicircle at the intermediate frequency region is related to the charge transfer resistance (Rct) and interfacial capacitance at the electrode/electrolyte interface. The conductivity slightly decreased in the order of F-CQN-1-400 > F-CQN-1-500 > F-CQN-1-600 > F-CQN-1-700. Thus, the high nitrogen content is benefit for a higher conductivity. 
Table S2 Summary of the representative organic cathode materials for lithium ion batteries.

\begin{tabular}{llllll}
\hline Materials & Voltage $(\mathrm{V})$ & $\begin{array}{l}\text { Capacity } \\
(\mathrm{mAh} / \mathrm{g})\end{array}$ & $\begin{array}{l}\text { Rate Capability } \\
(\mathrm{mAh} / \mathrm{g})\end{array}$ & $\begin{array}{l}\text { Cycling life } \\
\text { (Number of cycles) }\end{array}$ & $\begin{array}{l}\text { Reference } \\
\text { PPy/FC }\end{array}$ \\
DMTS & $1.5 \sim 4$ & 140 & 110 at $0.4 \mathrm{~A} / \mathrm{g}$ & 100 & $\mathrm{~S} 2$ \\
PTMA & $1.7 \sim 2.7$ & 658 & 317 at $0.849 \mathrm{~A} / \mathrm{g}$ & 50 & $\mathrm{~S} 3$ \\
DTT & $2 \sim 4$ & 222 & 80 at $200 \mathrm{C}$ & 20000 & $\mathrm{~S} 4$ \\
PBQS & $1.5 \sim 3$ & 292 & 220 at $0.285 \mathrm{~A} / \mathrm{g}$ & 200 & $\mathrm{~S} 5$ \\
DAAQ-COFs & $1.5 \sim 4$ & 275 & 198 at $5 \mathrm{~A} / \mathrm{g}$ & 1000 & $\mathrm{~S} 7$ \\
Cyclohexanehexone & $1.5 \sim 4$ & 145 & 72.5 at $3 \mathrm{~A} / \mathrm{g}$ & 1800 & $\mathrm{~S} 8$ \\
PPTC & $1 \sim 4$ & 902 & 382 at $0.5 \mathrm{~A} / \mathrm{g}$ & 100 & $\mathrm{~S} 9$ \\
DCBQ & $1.5 \sim 3.5$ & 196 & 137.1 at $1 \mathrm{~A} / \mathrm{g}$ & 300 & $\mathrm{~S} 10$ \\
2D PPTODB COFs & $1.5 \sim 4$ & 206.9 & 82.1 at $0.2 \mathrm{~A} / \mathrm{g}$ & 1000 & $\mathrm{~S} 11$ \\
BQ1-COF & $1.5 \sim 3.5$ & 198 & 98 at $1.5 \mathrm{~A} / \mathrm{g}$ & 150 & $\mathrm{~S} 12$ \\
PDPPD & $1.2 \sim 3.5$ & 502 & 170.7 at $7.73 \mathrm{~A} / \mathrm{g}$ & 1000 & $\mathrm{~S} 13$ \\
BBQB & $2.5 \sim 4.2$ & 102 & 84 at $100 \mathrm{C}$ & 1000 & $\mathrm{~S} 14$ \\
p-DPPZ & $1.6 \sim 3.5$ & 367 & 171 at $3 \mathrm{C}$ & 100 & S15 \\
2D-PAI@CNT & $2.5 \sim 4.5$ & 150 & 65 at $5 \mathrm{C}$ & 500 & S16 \\
F-CQN-1-600 & $1.5 \sim 3.5$ & 104.4 & 95 at $2 \mathrm{~A} / \mathrm{g}$ & 8000 & This work \\
\hline
\end{tabular}


Table S3 EIS fitting results using the circuit as shown below.

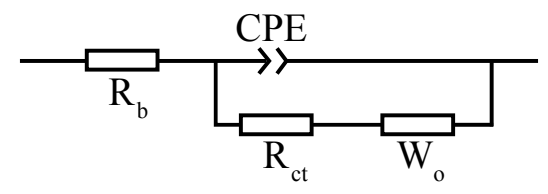

\begin{tabular}{llllllll}
\hline Samples & $\mathrm{Rb}(\Omega)$ & CPE-T $(\mathrm{F})$ & $\mathrm{CPE}-\mathrm{P}$ & $\mathrm{Rct}(\Omega)$ & W-R $(\Omega)$ & W-T $(\mathrm{S})$ & W-P \\
\hline CQN-600-before cycle & 3.19 & $1.15 \times 10-5$ & 0.83 & 175.6 & 66.53 & 3.68 & 0.40 \\
CQN-600-after cycle & 3.79 & $1.58 \times 10-5$ & 0.81 & 84.62 & 56.73 & 2.03 & 0.36 \\
CQN-700-before cycle & 3.27 & $1.50 \times 10-5$ & 0.82 & 168.10 & 185.10 & 7.54 & 0.34 \\
CQN-700-after cycle & 5.47 & $1.24 \times 10-5$ & 0.81 & 177.90 & 563.8 & 6.186 & 0.40 \\
\hline
\end{tabular}

$\mathrm{Rb}$ represents the solution resistance. The parallel combination of the interface charge transfer resistance (Rct) and the constant phase element (CPE) leads to a depressed semicircle in the corresponding Nyquist impedance plot. The constant phase element (CPE) is defined by CPE-T and CPE-P. If CPE-P equals 1 approximately, then the CPE is identical to a capacitor, Cdl. Here, CPE-P for these samples are all above 0.8 . Thus, the CPE-T values obtained in this work are close to Cdl.

$\mathrm{W}_{\mathrm{o}}$ represents open circuit Warburg impedance, which contains three parameters: W-R, W-T and W-P.

W-R: Diffusion resistance.

W-T: L2/D (s), is the diffusion interpretation of wurberg element and it is given as Wo-T=L2/D where L is effective diffusion thickness and $\mathrm{D}$ is diffusion coefficient of particle.

W-P: Warburg exponent. 

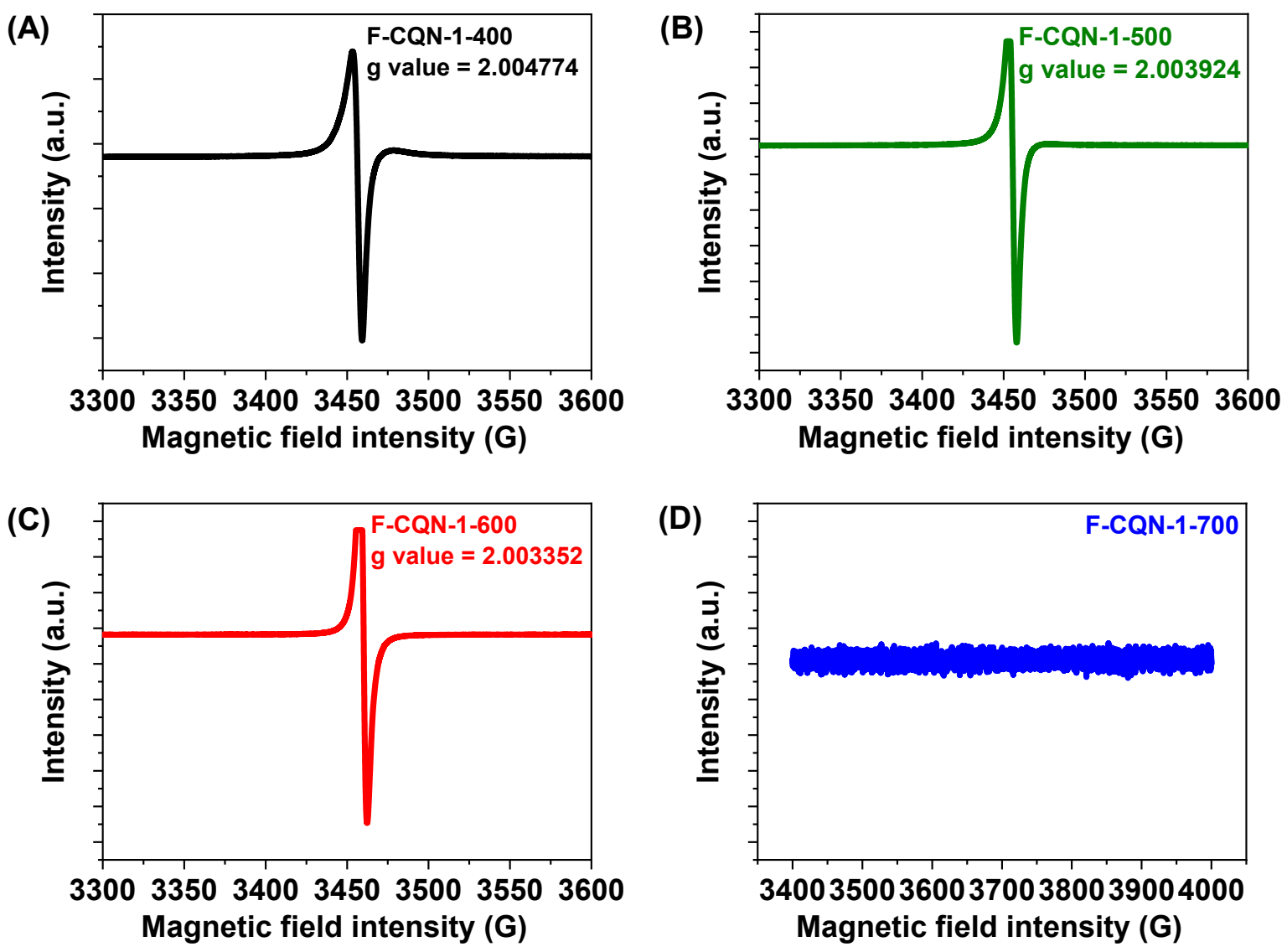

Figure S16 Room temperature electron paramagnetic resonance (EPR) spectra of (A) F-CQN-1-400, (B) F-CQN-1-500, (C) F-CQN-1-600, and (D) F-CQN-1-700.

The position was corrected using 2,2-diphenyl-1-picrylhydrazyl (DPPH) as the standard. The g value was calculated using Calculate by the expression: $h \nu=g * \mu * B$

Where, $\mathrm{h}=$ Planck's Constant $=6.626 \times 10^{-34} \mathrm{~J} \cdot \mathrm{s} ; \mathrm{v}=$ Microwave frequency $=9705.86 \mathrm{MHz}$ (used for measuring); $\mu=\mathrm{Bohr}$ Magneton $=9.27 \times 10^{-24} \mathrm{~J} / \mathrm{T}=9.27 \times 10^{-27} \mathrm{~J} / \mathrm{mT} ; \mathrm{B}=$ Magnetic field strength $=3463 \mathrm{G}=3463 \times 10^{-4} \mathrm{~T}=3463 \times 10^{-7} \mathrm{mT}$. 
(A)

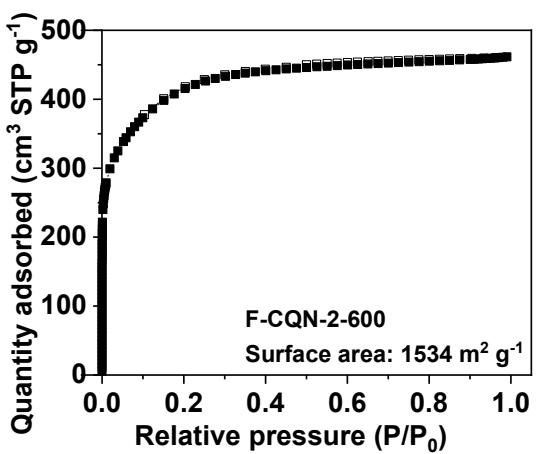

(C) 600

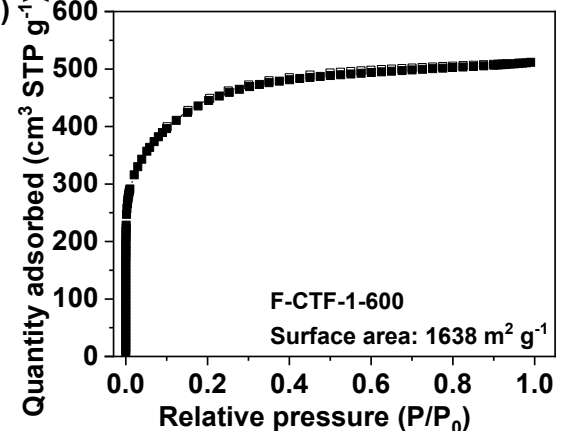

(E)

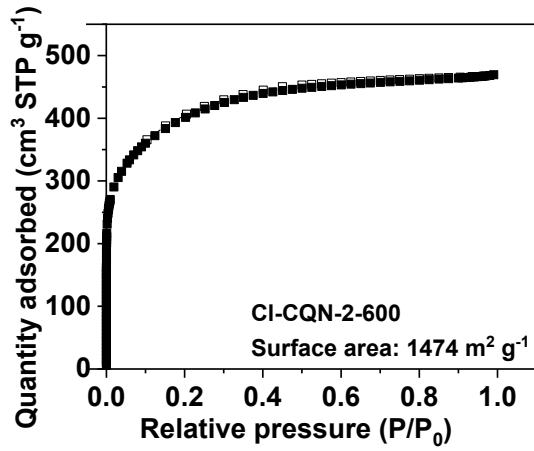

(B)

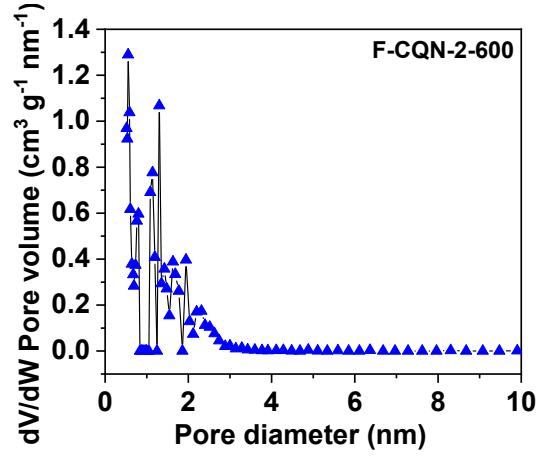

(D)

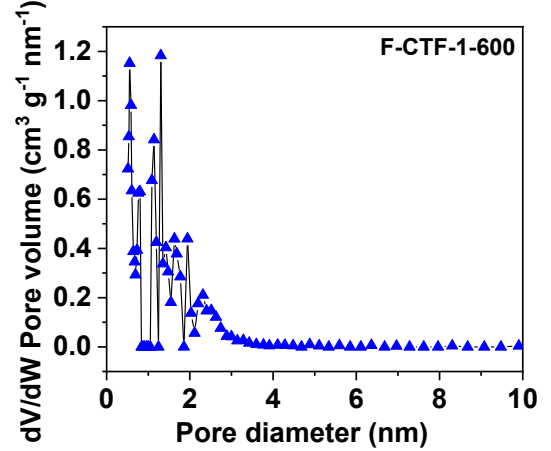

(F)

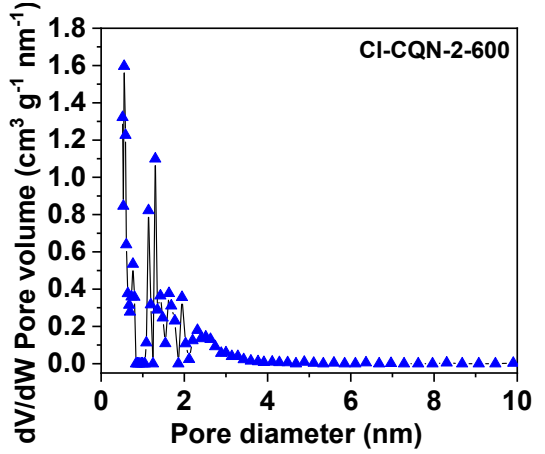

Figure S17 (A, B) $\mathrm{N}_{2}$ adsorption and desorption isotherm curves at $77 \mathrm{~K}$ and Pore-size-distribution curves of F-CQN-2-600, (C, D) F-CTF-1-600, and (E, F) Cl-CQN-2-600. 
(1) Xiang, Z.; Wang, Z.-Y.; Ren, T.-B.; Xu, W.; Liu, Y.-P.; Zhang, X.-X.; Wu, P.; Yuan, L.; Zhang, X.-B. A general strategy for development of a single benzene fluorophore with full-color-tunable, environmentally insensitive, and two-photon solid-state emission. Chem. Commun. 2019, 55 (76), 11462.

(2) Zhou, M.; Qian, J.; Ai, X.; Yang, H. Redox-Active Fe(CN)64--Doped Conducting Polymers with Greatly Enhanced Capacity as Cathode Materials for Li-Ion Batteries. 2011, 23 (42), 4913.

(3) Wu, M.; Cui, Y.; Bhargav, A.; Losovyj, Y.; Siegel, A.; Agarwal, M.; Ma, Y.; Fu, Y. Organotrisulfide: A High Capacity Cathode Material for Rechargeable Lithium Batteries. 2016, 55 (34), 10027.

(4) Guo, W.; Yin, Y.-X.; Xin, S.; Guo, Y.-G.; Wan, L.-J. Superior radical polymer cathode material with a two-electron process redox reaction promoted by graphene. Energy \& Environmental Science 2012, 5 (1), 5221.

(5) Ma, T.; Zhao, Q.; Wang, J.; Pan, Z.; Chen, J. A Sulfur Heterocyclic Quinone Cathode and a Multifunctional Binder for a High-Performance Rechargeable Lithium-Ion Battery. Angew. Chem. Int. Ed. 2016, 55 (22), 6428.

(6) Song, Z.; Qian, Y.; Zhang, T.; Otani, M.; Zhou, H. Poly(benzoquinonyl sulfide) as a High-Energy Organic Cathode for Rechargeable Li and Na Batteries. Advanced Science 2015, 2 (9), 1500124.

(7) Wang, S.; Wang, Q.; Shao, P.; Han, Y.; Gao, X.; Ma, L.; Yuan, S.; Ma, X.; Zhou, J.; Feng, X.; Wang, B. Exfoliation of Covalent Organic Frameworks into Few-Layer Redox-Active Nanosheets as Cathode Materials for Lithium-Ion Batteries. Journal of the American Chemical Society 2017, 139 (12), 4258.

(8) Lu, Y.; Hou, X.; Miao, L.; Li, L.; Shi, R.; Liu, L.; Chen, J. J. A. C. I. E. Cyclohexanehexone with Ultrahigh Capacity as Cathode Materials for Lithium-Ion Batteries. Angew. Chem. Int. Ed. 2019, 58 (21), 7020.

(9) Li, Q.; Li, D.; Wang, H.; Wang, H.-g.; Li, Y.; Si, Z.; Duan, Q. Conjugated Carbonyl Polymer-Based Flexible Cathode for Superior Lithium-Organic Batteries. ACS Applied Materials \& Interfaces 2019, 11 (32), 28801.

(10) Lyu, H.; Jafta, C. J.; Popovs, I.; Meyer, H. M.; Hachtel, J. A.; Huang, J.; Sumpter, B. G.; Dai, S.; Sun, X.-G. A dicyanobenzoquinone based cathode material for rechargeable lithium and sodium ion batteries. Journal of Materials Chemistry A 2019, 7 (30), 17888.

(11) Yao, C.-J.; Wu, Z.; Xie, J.; Yu, F.; Guo, W.; Xu, Z. J.; Li, D.-S.; Zhang, S.; Zhang, Q. Two-Dimensional (2D) Covalent Organic Framework as Efficient Cathode for Binder-free Lithium-Ion Battery. ChemSusChem 2020, 13 (9), 2457.

(12) Wu, M.; Zhao, Y.; Sun, B.; Sun, Z.; Li, C.; Han, Y.; Xu, L.; Ge, Z.; Ren, Y.; Zhang, M.; Zhang, Q.; Lu, Y.; Wang, W.; Ma, Y.; Chen, Y. A 2D covalent organic framework as a high-performance cathode material for lithium-ion batteries. Nano Energy 2020, 70, 104498.

(13) Obrezkov, F. A.; Shestakov, A. F.; Traven, V. F.; Stevenson, K. J.; Troshin, P. A. An ultrafast charging polyphenylamine-based cathode material for high rate lithium, sodium and potassium batteries. Journal of Materials Chemistry A 2019, 7 (18), 11430.

(14) Yang, J.; Xiong, P.; Shi, Y.; Sun, P.; Wang, Z.; Chen, Z.; Xu, Y. J. A. F. M. Rational Molecular Design of Benzoquinone-Derived Cathode Materials for High-Performance Lithium-Ion Batteries. Advanced Functional Materials 2020, 30 (15), 1909597.

(15) Dai, G.; Wang, X.; Qian, Y.; Niu, Z.; Zhu, X.; Ye, J.; Zhao, Y.; Zhang, X. Manipulation of conjugation to stabilize $\mathrm{N}$ redox-active centers for the design of high-voltage organic battery cathode. Energy Storage Materials 2019, 16, 236.

(16) Wang, G.; Chandrasekhar, N.; Biswal, B. P.; Becker, D.; Paasch, S.; Brunner, E.; Addicoat, M.; Yu, M.; Berger, R.; Feng, X. J. A. M. A crystalline, 2D polyarylimide cathode for ultrastable and ultrafast Li storage. 2019, 31 (28), 1901478. 